\title{
A New Dynamic Building Health Monitoring Method Based on the Hilbert-Huang Transform
}

\author{
Sheng-Chung $\mathrm{Su}^{1,2, *}$, Kuo-Liang $\mathrm{Wen}^{1}$, and Norden E. Huang ${ }^{3}$ \\ ${ }^{1}$ Institute of Geophysics, National Central University, Taiwan \\ ${ }^{2}$ Seismological Center, Central Weather Bureau, Taiwan \\ ${ }^{3}$ Research Center for Adaptive Data Analysis, National Central University, Taiwan
}

Received 16 April 2012, accepted 26 November 2013

\begin{abstract}
The theoretical solution for a Multiple-Degree-Of-Freedom (MDOF) structure is composed of a combination of several individual modes. When we demonstrate the actual response directly on the time-frequency spectrum, the energy distribution is usually concentrated at some range of frequencies, with the temporal variations of each band clearly shown. Those variations in the frequencies are the actual structure performances even though those "modal behaviors" are not coming from the theoretical solutions. Using the Hilbert-Huang Transform (HHT) the modal behaviors can be obtained easily by directly reading the time-frequency spectrum. To find Structural-Health-Monitoring (SHM) information, some numerical steps are found helpful. Including the signal enhancement skills, the time-frequency domain amplification function (T.F.AF), the modal temporal variation curve (MTVC) and the instantaneous frequency application. We develop a new method called the HHT SHM method; both experiment measurement and building observation are used to show the performance and method-validation. The procedures are described as follows. The original signal is first transferred into the wave-propagating properties, the T.F.AF. The T.F.AF can give dynamic parameter results through all phases in an earthquake event. After adopting useful modal information from the T.F.AF, which is called the MTVC. The MTVC contains detailed SHM information that enables observers to read the modal behavior. This is a new way to explore SHM information from actual records. These MTVCs can be used to explore the vivid differences in structure healthy conditions that might be ignored by other observers.
\end{abstract}

Key words: HHT, SHM, Vibration-based analysis, Strong-motion

Citation: Su, S. C., K. L. Wen, and N. E. Huang, 2014: A new dynamic building health monitoring method based on the Hilbert-Huang Transform. Terr. Atmos. Ocean. Sci., 25, 289-318, doi: 10.3319/TAO.2013.11.26.01(T)

\section{INTRODUCTION}

Building health monitoring is necessary in order to maintain optimal utility and safety. Regular maintenance and strategic retrofitting prolong the building service period and also prevent dramatic losses caused by catastrophic disasters. This is especially true for the buildings in earthquake prone regions. Structural models help us to explore basic mechanical behaviors. However, such assessment is limited to the linear performances far from the critical conditions. It is obvious that the basic model cannot explain nonlinear and nonstationary peculiarities in the building when it approaches the critical conditions near the failure mode. This encourages us to develop a more accurate alter-

\footnotetext{
* Corresponding author

E-mail: scsunew2013@gmail.com
}

native approach to clarify the building performance under realistic conditions.

We have to consider the real structural health condition estimation under more complicated situations and influential forces to enhance the health monitoring performance, such as: (1) The complicated excitation force might be nonstationary and nonlinear. (2) Many appended intermittent situations on construction sites (for example, noisy traffic, flood excavation, wind-induced vibration...etc.) are never considered in the model analysis. (3) The aging and temperature effects on the construction material and structure, which might lead to serious consequences at any moment. Those complications are not included in the mathematical formulation and model analysis, but their results should not be neglected, for the cumulated effects could have dire consequences.

In this paper, we will introduce a new approach to 
include some of these complications into full consideration in the nonlinearity and nonstationarity forcing functions as well as the building responses. Instead of idealizing models this new approach will use the actual in situ time history data, which will contain all of the complications and particularities of any given building.

Some researchers tried to read the Structural-HealthMonitoring (SHM) information from the in situ data using the time-frequency spectrum. The strong-motion and realtime record data gathered from the Millikan Library (MIK) building, Caltech, California were analyzed by Bradford et al. and Clinton et al. (2006) using various kinds of time-frequency spectra. The temporal variation in the dominate frequency from the time-frequency spectra from the roof were taken as the dynamic modal behavior of the building. The artificial finite-element analytical model and real building in situ records were adopted to verify various kinds of timefrequency spectra. Their findings were: (1) allowing for the evolution of frequency content in a signal, the Wigner-Ville Distribution with the Reduced Interference Distribution (RID) provides useful structural information about the damage estimation. (2) From the dominate frequency observation at the top floor of the MIK building the dominate frequency wandering was discussed from the long-term, and transient aspects within the external and internal reasons about the structural and nonstructural influences. (3) The wandering in the natural frequencies is significant for the engineering community, especially in engineering practice. A linear structural behavior is assumed for ambient and small motions, but the MIK result was clearly not the case. These findings do help a lot in identifying the onset of timefrequency spectrum dynamic property changes.

There are several methods used to show the earthquake waveform in a time-frequency spectrum. Bradford et al. (2006) used several kinds of time-frequency spectra in a nonstationary signal, including the Spectrogram (Short Time Fourier Transform), the Scalogram (Continuous Morlet Wavelet), the Wigner-Ville Distribution, the RID and the Smoothed Pseudo Wigner-Ville Distribution. The RID was selected to demonstrate the nonlinear building earthquake response data. Besides the RID, Huang et al. (1998) reviewed the Spectrogram, the Wavelet analysis, the Wigner-Ville Distribution, the Evolutionary Spectrum, the empirical orthogonal function expansion (EOF) and the HilbertHuang Transform (HHT) for the nonstationary signal. They suggested the HHT as the adequate time-frequency method for the nonstationary and nonlinear signal. In light of the aforementioned results we used the HHT to show the earthquake waveform on a time-frequency spectrum.

Structural damage usually results in a loss of structural stiffness, which is characterized by a significant drop in the natural frequency. When the structure suffers from earthquake excitation (Huang et al. 2001; Wen et al. 2001), the nonlinear and nonstationary earthquake wave propagates from the basement upward to the top of the building. Taking a concept similar to the aforementioned Heaton's MIK observation into account, we consider the response at the top of the floor and the input motion at the basement at the same time.

The HHT can fully consider the nonlinear and nonstationary nature of the forcing functions and building responses in time-frequency representations which are known as the Hilbert Spectrum (HSP). The useful SHM information on the temporal and frequency domain can be directly obtained from the HSPs. In order to distinguish the present approach from the traditional ones, we designated the present structural modal behavior result as the "Modal Temporal Variation Curve (MTVC)." This paper is organized as follows.

After the introduction a section on the new data analysis methodology will be presented in the next chapter, including brief summaries on the HHT, Empirical Mode Decomposition (EMD) and the Hilbert Spectral analysis. We specifically introduce an ensemble approach to heighten the energy evolution accuracy along the temporal axis with instantaneous frequency, structural dynamics and structure health monitoring parameters extraction. In the third chapter we introduce the testifying data sets. In the fourth chapter we integrate the whole method and explain the method in great detail. In the fifth chapter we demonstrate validation of the new HHT SHM methodology, including both shaking-table and real building data. A brief discussion and conclusion is given in the sixth chapter.

\section{THE NUMERICAL METHODS OF THE NEW METHODOLOGY}

Several novel numerical techniques and methods are introduced in this research. There are five numerical analyses methods that serve particular requirements. Those methods are described in the following paragraphs, $2.1-2.5$, respectively:

2.1 Time-frequency domain presentation of the HHT. 2.2 Signal enhancement for HHT through the ensemble.

2.3 The Instantaneous Frequency extraction.

2.4 Structural dynamic modal parameters extraction.

2.5 SHM parameters analysis.

\subsection{Hilbert-Huang Transform}

The HHT consists of two parts: the adaptive EMD method and the instantaneous frequency in the Hilbert spectral analysis. This method was first introduced by Huang et al. (1998). The critical new introduced concepts are the adaptively defined basis and physically meaningful instantaneous frequency computation through the Hilbert transform. A brief summary of the method is given below.

\subsubsection{The Hilbert Transform}

The Hilbert transform for an arbitrary time series, $X(t)$, is 
calculated as the analytical pair, $Y(t)$. Although a formal phase function could result from this operation, to have a meaningful instantaneous frequency to utilize the real Hilbert transform advantage only became obvious after Huang et al. (1998) introduced the Empirical Mode Decomposition method.

\subsubsection{The Empirical Mode Decomposition Method (EMD)}

Contrary to almost all previous methods, this new method is intuitive, direct, a posteriori and adaptive, with the basis of the decomposition based on and derived from the data. Each of the oscillatory modes produced is represented by an Intrinsic Mode Function (IMF) with the following definitions: in the whole data set the number of extremes and the number of zero-crossings must either equal or differ at most by one and at any point, the mean value of the envelope defined by the local maxima and the envelope defined by the local minima is zero.

With this definition one can decompose any data by repeating the sifting process into a set of IMFs and the residue, $r_{n}$. Here we left out the residue in Eq. (1), $r_{n}$, on purpose, for it is either a monotonic function or a constant.

$X(t)=\left(\sum_{j=1}^{n} c_{j}\right)+r_{n}$

\subsubsection{The Hilbert Spectral Analysis}

Having obtained the IMF components, we can apply the Hilbert Transform to each IMF component and compute the instantaneous frequency accordingly. After performing the Hilbert transform on each IMF component, the original data can be expressed as the real part, RP, in the following form:

$X(t)=\operatorname{RP} \sum_{j=1}^{n} a_{j}(t) e^{i \int \omega_{j}(t) d t}$

Equation (2) gives both amplitude and frequency of each component as functions of time. The same data if expanded in Fourier representation would be Eq. (3),

$X(t)=\operatorname{RP} \sum_{j=1}^{\infty} a_{j} e^{i \omega_{j} t}$

with both $a_{j}$ and $\omega_{j}$ constants. The contrast between Eqs. (2) and (3) is clear: the IMF represents a generalized Fourier expansion. The variable amplitude and the instantaneous frequency have not only greatly improved the efficiency of the expansion, but also enabled the expansion to accommodate nonlinear and non-stationary data. With IMF expansion the amplitude and the frequency modulations are also clearly separated. Thus, we have broken through the restriction of the constant amplitude and fixed frequency Fourier expansion and arrived at a variable amplitude and frequency representation on the time axis. This frequencytime distribution of the amplitude is designated as the HSP, $H(\omega, t)$, or simply HSP.

\subsection{Signal Enhancement for HHT Through Ensemble}

To read the SHM information from the time-frequency spectrum directly, the HSP must be precise and clear. Two signal processing skills were used to improve the performance of EMD and HSP here:

(1) Ensemble Empirical Mode Decomposition (EEMD) (Wu and Huang 2004, 2009): one of the major drawbacks of the original EMD is the frequent appearance of mode mixing, which is defined as a single IMF either consisting of signals of widely disparate scales, or a signal of a similar scale residing in different IMF components. The EEMD, which defines the true IMF components as the mean of an ensemble of trials, each consisting of the signal plus a white noise of finite amplitude. Based on the study of white noise characteristics, the addition of the white noise actually serves to establish a set of temporal scales for the extracted IMFs.

(2) Ensemble Hilbert Spectrum (EHSP): the ensemble approach is only applicable when the sampling frequency is several times higher than the object; the method had been used and studied by Huang et al. (2006). For instance, the sample rate of strong-motion acceleration record is $200 \mathrm{~Hz}$, the object we want to analyze is about 0 - $10 \mathrm{hz}$. So we can down-sample the data into several parts. Taking each part as an independent event and proceeding with EEMD, then we took the mean of the HSP as the result. Essentially, the Nyquist frequency of the down-sample data should be checked.

With aforementioned two HHT enhancement techniques, the HSP of the strong-motion records from the building were greatly improved. The differences in EMD, EEMD and EHSP results are shown in Fig. 1.

\subsection{The Instantaneous Frequency Extraction}

Both the energy and frequency variations in the original waveform are demonstrated simultaneously in the HSP. In order to show only the structural dominate frequency variation, the energy variations should be separated from the HSP first. Physically speaking, the instantaneous frequency on the timefrequency domain amplification function (T.F.AF) means the dominate frequency of the structure. This procedure is particularly applicable for the nonstationary waveform. The earthquake and associated response are both the pattern.

For each moment, in the specific frequency band, we set the magnitude of the maximum energy density as one; we express this numerical calculation using the notation 
"N.S[HSP]," and call it as "Temporal Energy Normalization."

\subsection{Structural Dynamic Modal Parameters Extraction}

To read the MTVC from the HSP directly and correctly, some extraction skills were applied. There were two steps for extracting the structural dynamic modal parameters from the T.F.AF here. Those steps were necessary for the strong-motion building earthquake records.

(1) Finding the Centroid of a Fixed frequency-band Range for the frequency temporal curve (abbreviated as CFR): the HSP decomposes the energy of original signal into a distribution energy density in the time-frequency plane. Therefore, it is possible to find the Centroid location about the energy density for each moment. The energy density of the HSP at time $t$ and the frequency $f$ is $e(t, f)$, the Centroid of specific frequency band range $k-m$ (for the $i^{\text {th }}$ mode) can be defined as Eq. (4).

$$
\mathrm{CFR}_{i,(k \sim m)}(t)=\frac{\sum_{i=k}^{i=m} e\left(t, f_{i}\right) \cdot f_{i}}{\sum_{i=k}^{i=m} e\left(t, f_{i}\right)}
$$

(2) White Noise Filter (WNF): the white noise signal from all different sources could exist everywhere besides the structural signal on the HSP. By our observational experiences, for a strong earthquake the responding structural modal energy is about ten times greater than the ambient surrounding white noise. The white-noise in the CFR should be removed. The threshold of the WNF is
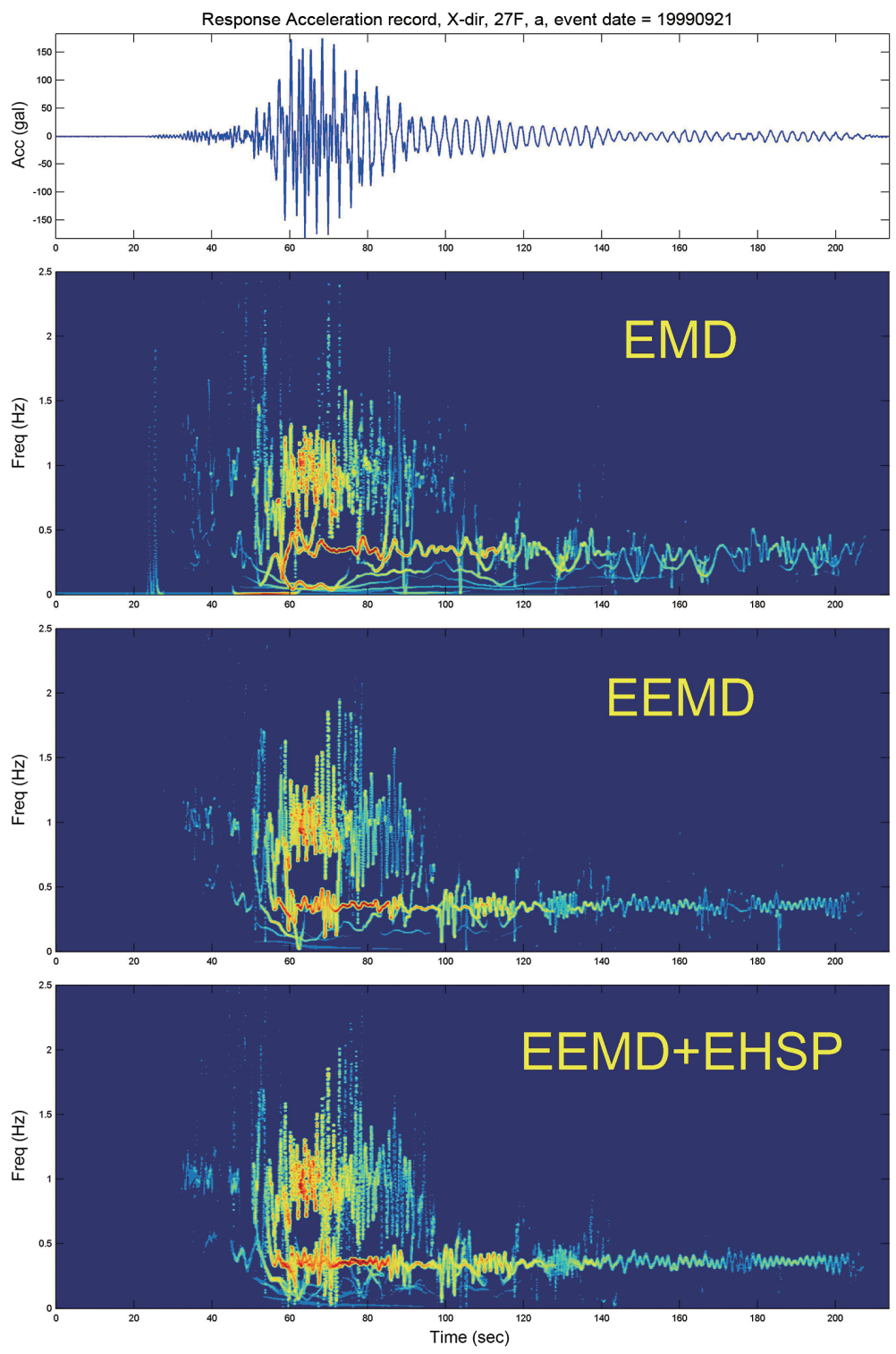

Fig. 1. The improvements of Hilbert Spectrum. 
defined as the ambient energy density (at the beginning of the record, the quiet segment) multiply by a constant; we defined the constant as eleven in this research. Physically speaking, we think the modal behavior signal is good for extraction when the energy density is eleven times beyond the ambient noise. The WNF processing technique could benefit the strong-motion data presentation but it is not necessary for the ambient data, for this data are similar to the white noise itself.

The building is acting like a filter. The T.F.AF are calculated from the input and output of the filter. During the earthquake, the instantaneous frequency and the energy density distribution on the T.F.AF are the wave-propagating results from the structure. Some of the filtering characteristics are the appearance of the modes. These two processing steps help to extract modal information from the T.F.AF. We assumed the modal behavior is acting like the CFR after the mode is initiated. Using these two numerical steps in this section, the modal behavior of the $i^{\text {th }}$ mode can be written as $\mathrm{MTVC}_{i}(t)$ using Eq. (5):

$$
\left.\operatorname{MTVC}_{i}(t)=\mathrm{WNF}_{\mathrm{CFR}}(t)\right]
$$

\subsection{The SHM Parameters Analysis and Adoptions}

Embarking on real building SHM work, we extract some useful parameters from the MTVC. These parameters are especially important for the healthy structure evaluation. For this condition there were no drastic differences in the T.F.AF and no apparent drop in the natural frequency. The mean value and the standard deviation value of the MTVC were defined as Integrity Index (II) and Nonlinearity Index (NI) separately, please see the Eqs. (6) and (7), for the $i^{\text {th }}$ mode:

$\mathrm{II}_{i}=\operatorname{mean}\left[\operatorname{MTVC}_{i}(t)\right]$

$\mathrm{NI}_{i}=\operatorname{std}\left[\mathrm{MTVC}_{i}(t)\right]$

The fact that the standard deviation value of MTVC could be used as an indicator for nonlinearity is based on the intrawave frequency modulation idea discussed by Huang et al. (1998). In fact, this intra-wave frequency modulation had been used as the base to quantify the degree of nonlinearity by Huang et al. (2013). Here we used the gross feature of the detailed intra-wave frequency modulation as an index for building nonlinearity. As for the mean MTVC frequency, it is a representation of the structure stiffness. The mean frequency could be used as a valuable structural stiffness indicator.

\subsection{The Total Map of the HHT SHM Method and its Validation}

A flowchart of all of the analysis steps in this new ap- proach is shown in Fig. 2, starting at the input and output amplification relationship. There are two different results, the T.F.AF and MTVC. First, the wave-propagating characteristics during the excitation are in the T.F.AF. Then, identify the T.F.A.F. features with structural concepts and mechanical theorems, useful T.F.AF is then extracted as the MTVC, the modal behavior of the structure.

Two data set were introduced to verify the new HHT SHM method. The shaking-table data was used to show the T.F.AF performance. The Tai-Power building 1994 - 2013 strong-motion observations were used to show the MTVC performance.

\section{THE TESTIFYING DATA SETS}

The measurements from the shaking-table and real building are introduced in the following paragraphs. Both can be classified as in situ records. The records are containing both environmental noise and the structure responses, which are different with the calculated model-simulated ones.

The shaking-table experiment data: The "pounding-set" experiment data (Lee and Chung 2012) was originally designed to observe the pounding behavior between two bridges. There were two Single-Degree-Of-Freedom (SDOF) models locating on the same shaking-table in a very close distance, please see Fig. 3. The left one was named as L01 within the dominate frequency $3.4 \mathrm{~Hz}$, and the right one was named as R02 within the dominate frequency $5.5 \mathrm{~Hz}$. The shakingtable was named as $\mathrm{C} 04$, governs the controlling excitation acceleration time history applied to the two SDOF structures. The data logging system was recorded at the sample rate $25 \mathrm{kHz}$, and the SDOF model showed the transient behavior under the sinusoid and earthquake excitations.

The building strong-motion data comes from the TaiPower building, consisting of 2 structures with the first 27 floors and the second 12 floors. The buildings are located in southern Taipei city. The building is the switching and controlling center for Taiwan electrical energy. The steelstructure buildings were designed and constructed in 1979 and 1982. There are 26 accelerometers instrumented in 1994 by the Central Weather Bureau (CWB). The sensor distribution is shown in Fig. 4. The data sampling rate is $200 \mathrm{~Hz}$. The CWB began strong-motion observations for the Tai-Power building on May 23, 1994. The DOS-compatible data-logging system was replaced by the WinXPcompatible data-logging system at the end of 2008. There are 155 earthquake events in the integrated data catalogue, please see the Appendix and Fig. 5. The structures were reinforced during 2009 - 2010 for the new seismic provision regulations for buildings in Taiwan. From January 1 of 2009 to February 2 of 2011 the buildings were under structural reinforcement construction work. With obvious structurereinforcing differences the data set can be the benchmark for actual building SHM performance. 


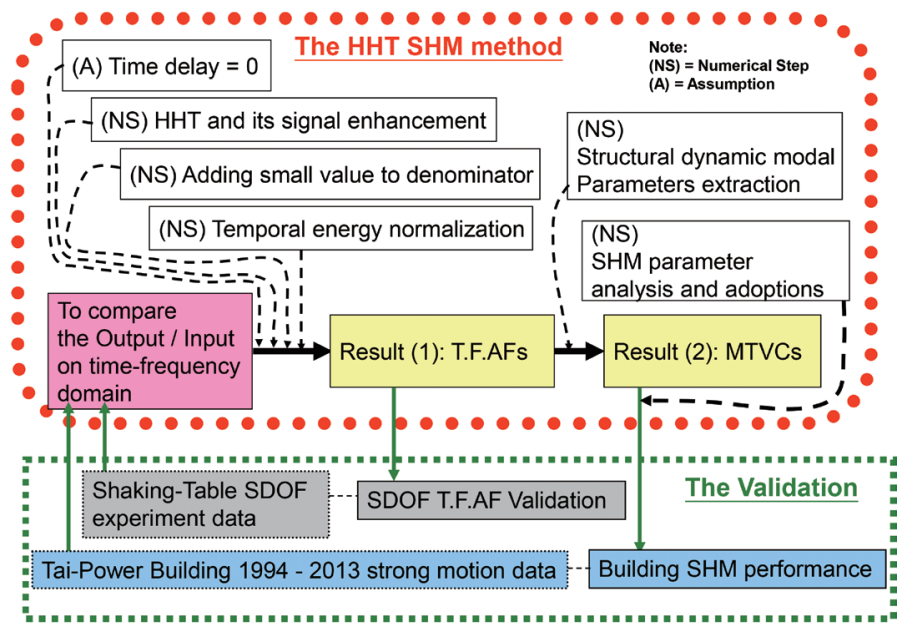

TOTAL FLOWCHART

Fig. 2. The flowchart of the all numerical steps in this analysis.

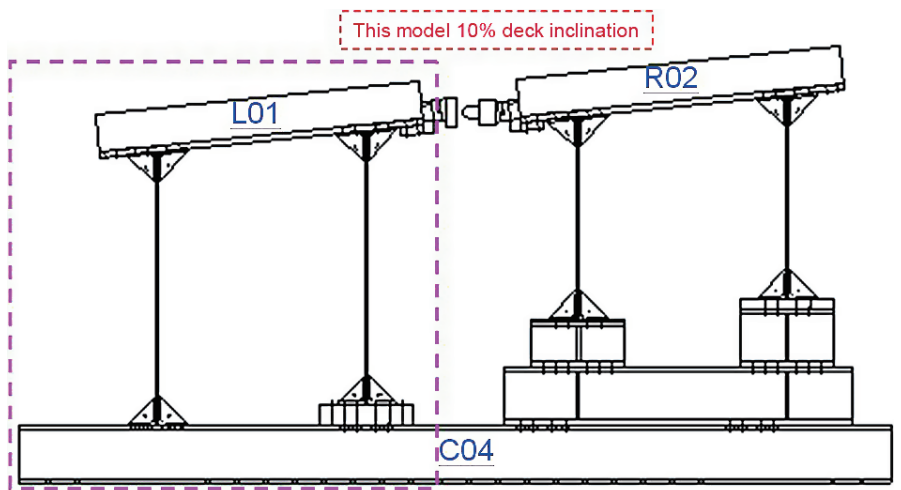

The Pounding Effect of Bridges with Inclined Decks

The dominate frequency of the 1D-SDOF structure: L01 - 3.4 Hz, R02 - 5.5 Hz

Fig. 3. The SDOF shaking-table experiment set L01 and C04 (the pounding set).

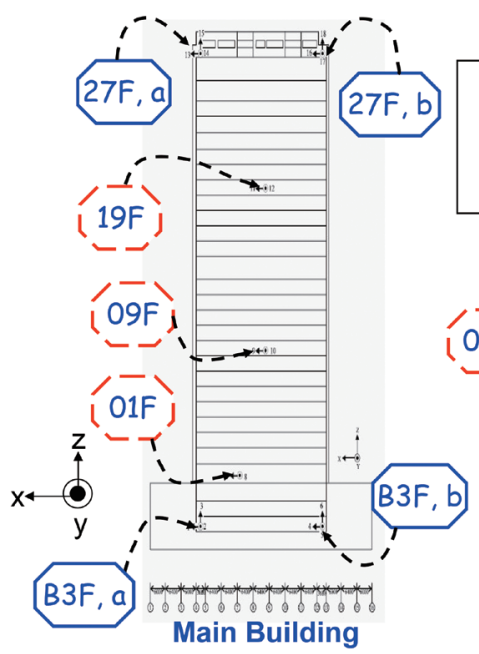

(Front View)

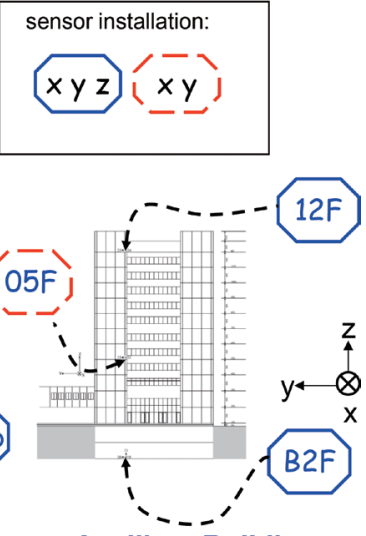

Auxiliary Building

(Front View)

The Instrument Plan of Tai-Power Building (TSMIP, TAPBA4, CWB)

Fig. 4. Tai-Power Building Station Instrument Plan. 

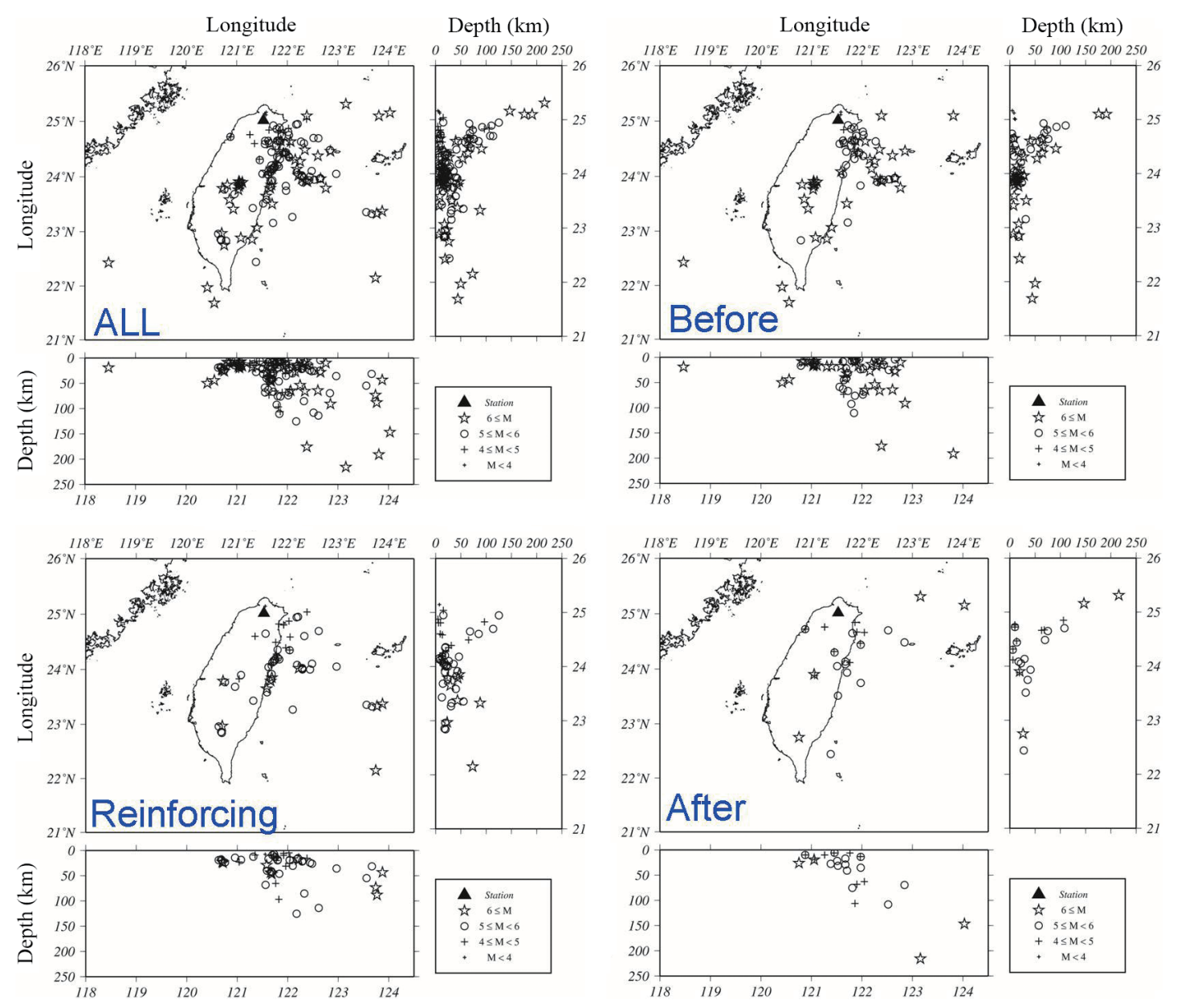

Fig. 5. Earthquake Hypocenter Location for 3 different structural stages.

\section{THE HHT SHM ANALYSIS}

We employed all of the data analysis techniques described in the previous section as the new "HHT SHM analysis" method. The results and the specific implications of each step during the analysis will be discussed in this section as: 4.1 Time-frequency domain presentation.

4.2 Time-Frequency domain Amplification Functions. 4.3 Temporal variations of modal dynamic parameters.

\subsection{Time-Frequency Domain Representation}

In the beginning before setting the amplification function as our main parameter, we examined the HSP and N.S[HSP] for the top floor (for instance, it is the $27 \mathrm{~F}$ of the main building). Figure $6 \mathrm{a}$ gives the 27F HSP and associated figures and Fig. $6 \mathrm{~b}$ gives the N.S[HSP] and associated figures. The strong-motion acceleration waveform and corresponding Hilbert Marginal Spectrums (along temporalaxis and frequency-axis) are plotted together with the timefrequency HSP (means Fig. 6a). The time-frequency HSP shows the energy distribution pattern on the time-frequency domain. The Hilbert Marginal Spectrum along temporal-axis (abbreviated as MS-T or M.S.-Time) is made by integration along the frequency-axis of the time-frequency spectrum. The MS-T result shows the energy distribution pattern along the time axis. The Hilbert Marginal Spectrum along the frequency-axis is the integration of HSP energy density along time-axis (abbreviated as MS-F or M.S.-Frequency) of the time-frequency spectrum. The MS-F result shows the energy distribution pattern along the frequency axis. Commonly, the MS-F is called the Marginal Hilbert Spectrum. Likewise, for Fig. 6b, the time-frequency HSP shows the instantaneous frequency distribution pattern on the time-frequency domain.

Both the input HSP and output HSP are very important. These two HSPs should be considered simultaneously and placed together. To show the wave-propagation properties of the structure under different earthquake excitation we decided to use the T.F.AF as the main SHM dynamic parameter.

\subsection{Time-Frequency Domain Amplification Functions (T.F.AF)}

Two amplification functions were defined here, the 
A.F.m and A.F.f, showing the energy density and the instantaneous frequency distribution patterns on the time-frequency domain separately.

\subsubsection{Two-Station Method: Finding the Amplification}

The earthquake energy is generated from hypocenter tectonic activities. The released energy passes through the underground geographic media, reaches the specific site conditions, impacts the foundation of structures and propagates upward to the other parts of the building. Taking our real building data set as the example, Eq. (8) depicts the structure excitation recording at the foundation (the third basement level in the main building: B3F). Considering the
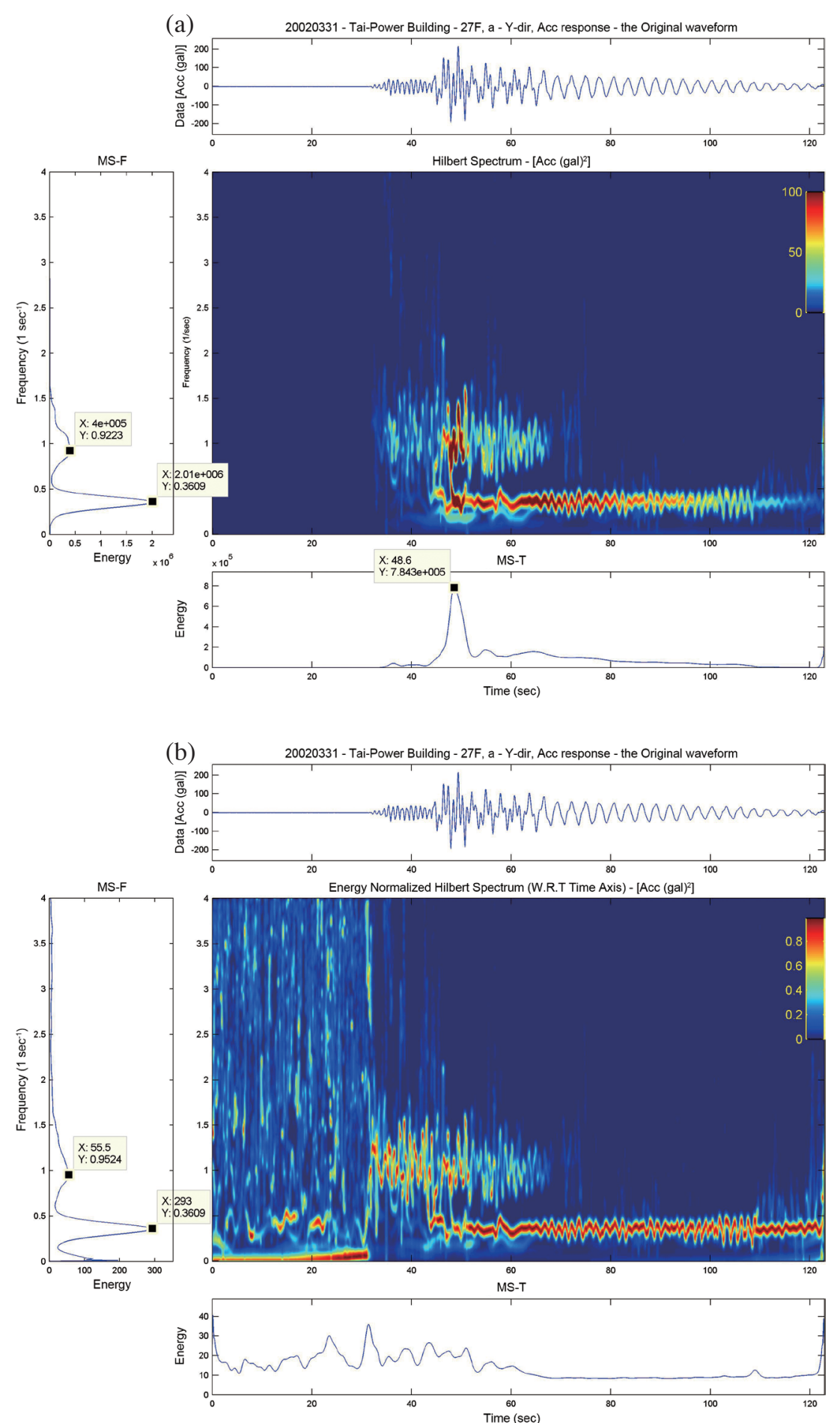

Fig. 6. (a) The HSP of Tai-Power building 27F, Y-dir on 20020331 event. (b) The N.S[HSP] of Tai-Power building 27F, Y-dir on 20020331 event. 
Borcherdt's (1970) concept on the frequency domain, the free-field earthquake response influenced by source, path, and site (abbreviated as $\mathrm{So}, \mathrm{Pa}, \mathrm{Si}$ ) factors are all included.

$R_{\mathrm{B} 3 \mathrm{~F}}(f)=$ F.F(So, $\left.\mathrm{Pa}, \mathrm{Si}\right)$

We then extended the Eq. (8) concept to introduce the response of the top of structure (the top floor of the main building: 27F ) in Eq. (9):

$R_{27 \mathrm{~F}}(f)=\mathrm{F} . \mathrm{F}(\mathrm{So}, \mathrm{Pa}, \mathrm{Si}) \times \operatorname{Str}(f)$

The structure's existence makes the extra term $\operatorname{Str}(f)$. Focusing on the structure's influence we define AF as the amplification function on the frequency domain in Eq. (10):

$\mathrm{AF}=R_{27 \mathrm{~F}}(f) / R_{\mathrm{B} 3 \mathrm{~F}}(f)=\operatorname{Str}(f)$

Here in Eq. (10) our attention is totally focused on the energy transmission within the building from its foundation to the building roof. The influence of source, path and site are implicitly included in the forcing terms at the foundation. Additionally, we expanded the original concept from frequency domain to time-frequency domain. The physical meaning still remains the same.

There are, however, some factors that should be considered. The total travelling length from the foundation at the bottom to the top of a building is about $20-500 \mathrm{~m}$, so the earthquake arrival time at different parts of the building could be different. This difference is usually small and we will neglect it.

There are two different scenarios observed on the earthquake waveform travel path from the foundation to the roof, the filtering and the keeping. The keeping means the rigid body motion during the vibration. The foundation movements and the roof response remain the same. In our observational experience this movement is slightly amplified at the roof for the free-confinement boundary condition. The filtering means most input waves are reduced but a few are drastically increased. The earthquake input wave is filtered and the roof vibrates only at the resonant frequency with amplified amplitude for a slender building. The distribution of these two scenarios on the T.F.AF depends on the geometry and stiffness of the structure. For a short or stiff object the keeping scenario is the major factor. For a slender or soft object the filtering scenario is a major factor. One should keep in mind that exploring the T.F.AF is the decomposition of the wave-propagation phenomenon.

\subsubsection{The Amplification Function of Wave-Propagation Magnitude (A.F.M)}

We will use the responses of two different floor posi- tions to investigate the amplification relationship between "input and output" in the time-frequency domain. For an earthquake acceleration time series, $X(t)$, we can calculate its HSP within aforementioned HHT ensemble techniques. The result is designated as $\mathrm{H}[X(t)]$. The amplification function in time frequency domain could be defined as Eq. (11):

$\mathrm{A} \cdot \mathrm{F} \cdot \mathrm{m}_{(27 \mathrm{~F})}=\frac{\mathrm{HSP}(27 \mathrm{~F})}{\mathrm{HSP}(\mathrm{B} 3 \mathrm{~F})}=\frac{H\left[X(t)_{27 \mathrm{~F}}\right]}{H\left[X(t)_{\mathrm{B} 3 \mathrm{~F}}\right]}$

Equation (11) shows the energy density T.F.AF under earthquake excitations from the foundation to roof (B3 - 27 $7^{\text {th }}$ floor). The A.F.m figure is shown in Fig. 7. The corresponding marginal spectrums, the input and output waveforms, the input and output HSPs are also plotted on the same figure.

There is a mathematical issue while we process the Eq. (11) division calculation. The division result will become "meaningless" while the denominator value is zero. To avoid this, we added a very little value to the denominator. In our case the denominator is the input (B3F) HSP, the numerator is the output (27F) HSP. Both the input and output HSP is a $500 \times 1000$ matrix which might contain zero in it. We find the maximum value of the input $500 \times 1000$ matrix and add 0.001 maximum to the whole matrix. This skill is used to avoid mathematical meaningless. Next, we will explore the details of the frequency perturbations in the following section.

\subsubsection{The Amplification Function of Wave-Propagation Frequency (A.F.F)}

The N.S. notation was explained in section 2.3. We apply this notation to Eq. (11). The result is shown in Eq. (12).

A.F. $f_{(27 F)}=N \cdot S\left[A \cdot F \cdot m_{(27 F)}\right]$

After the N.S calculation the frequency temporal variation on the HSP is clearly shown as in Fig. 8. From the A.F.f results we found that the variation in modal structural dynamic properties always occurs instantaneously.

Four different wave phase observations are noted in the strong-motion data. The four different sub segments are shown in Fig. 9 with the A.F.f on the time-frequency domain. By defining the Coda sub segment starting point the result helps us to discriminate free-vibration from force-vibration. The S-wave sub-segment of a strong-motion record should be the most important phase of earthquake-force-vibration for the building. The ending part of a strong-motion record is usually called the coda; containing free vibration information for the building. The instantaneous frequency pattern of the T.F.AF from different phases help to identify the keeping and filtering characteristics during the wave-propagating process. The peculiarity in each phase can be discussed using 


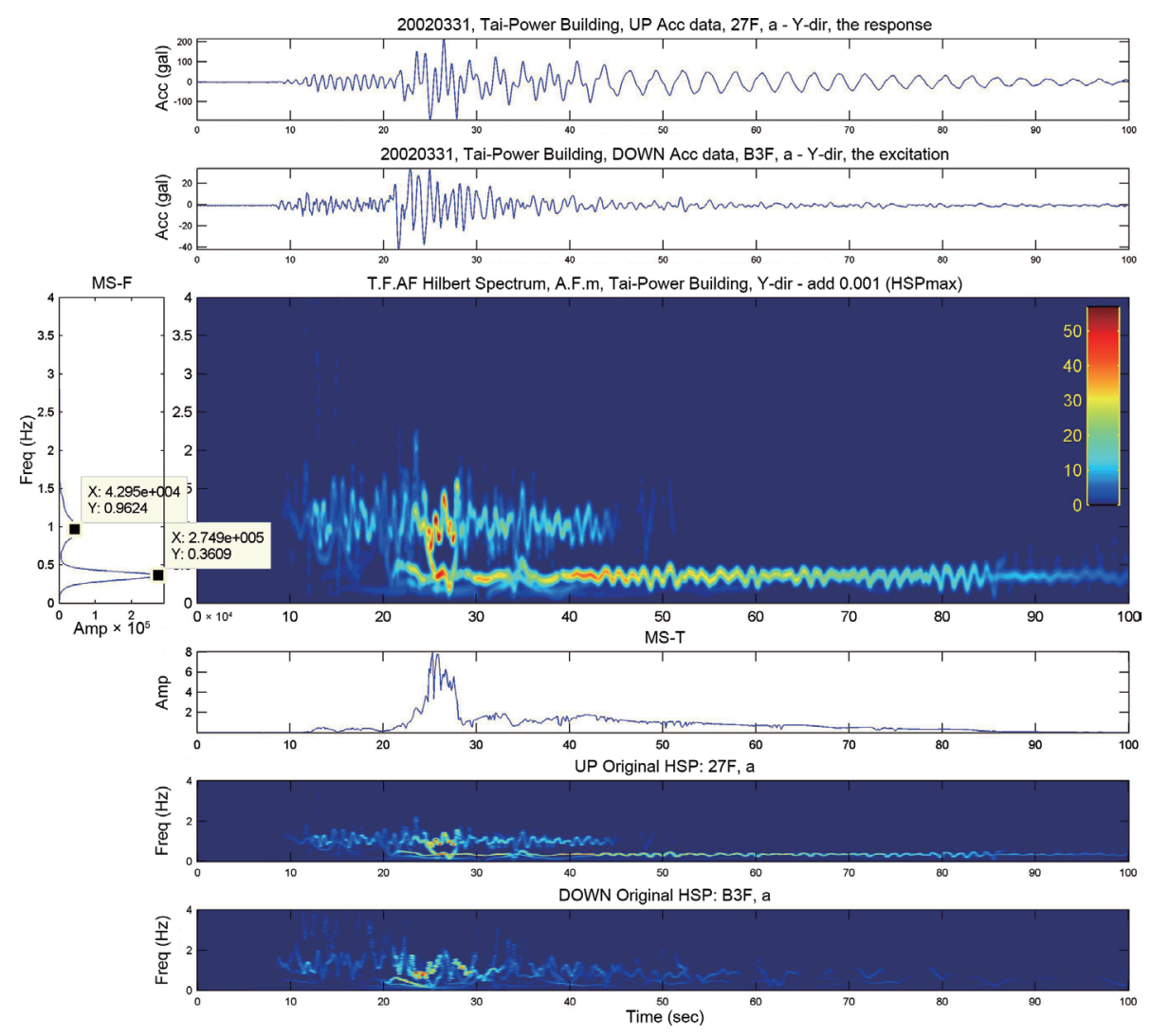

Fig. 7. The T.F.AF (A.F.m) of Tai-Power building Y-dir on 20020331 event.

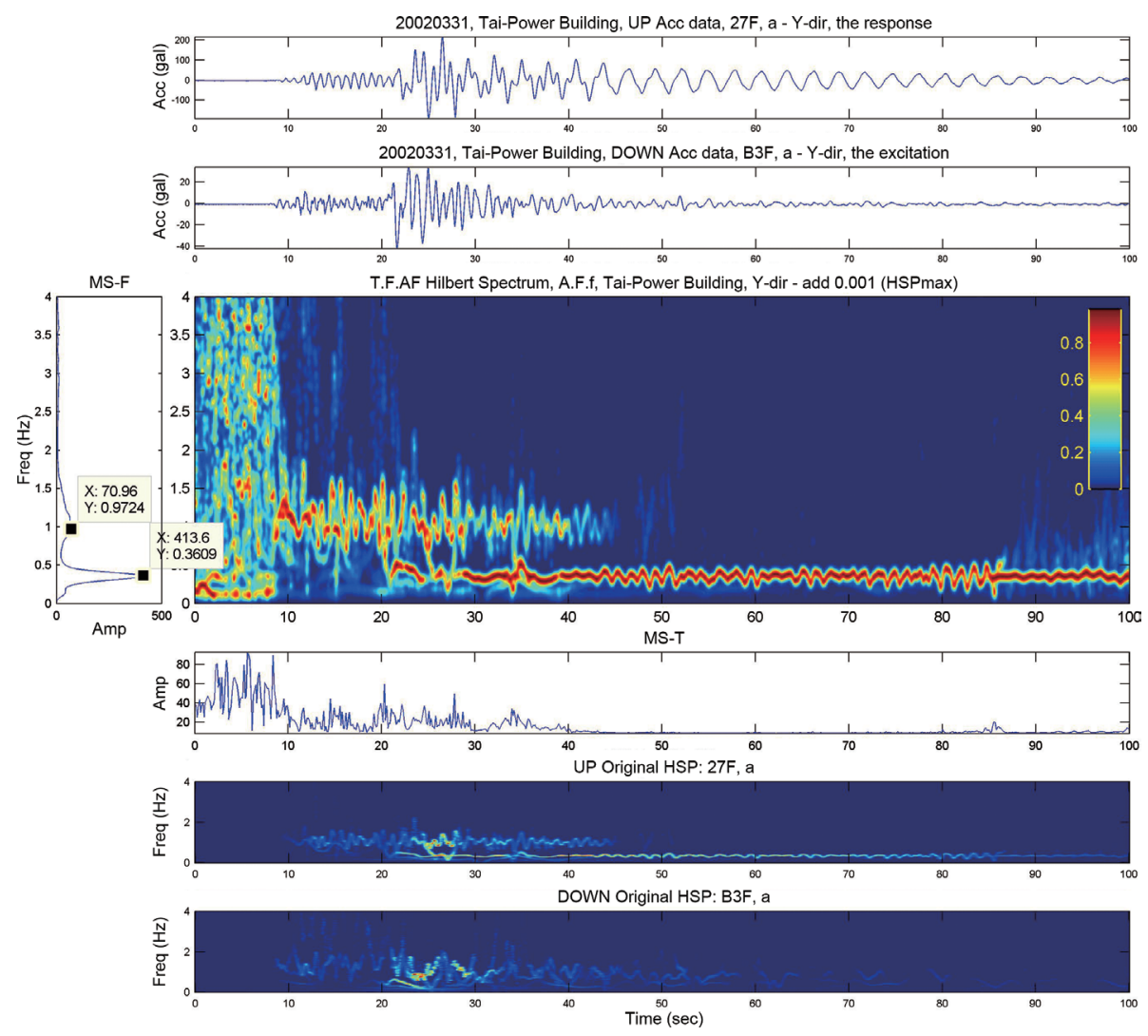

Fig. 8. The T.F.AF (A.F.f) of Tai-Power building Y-dir on 20020331 event. 

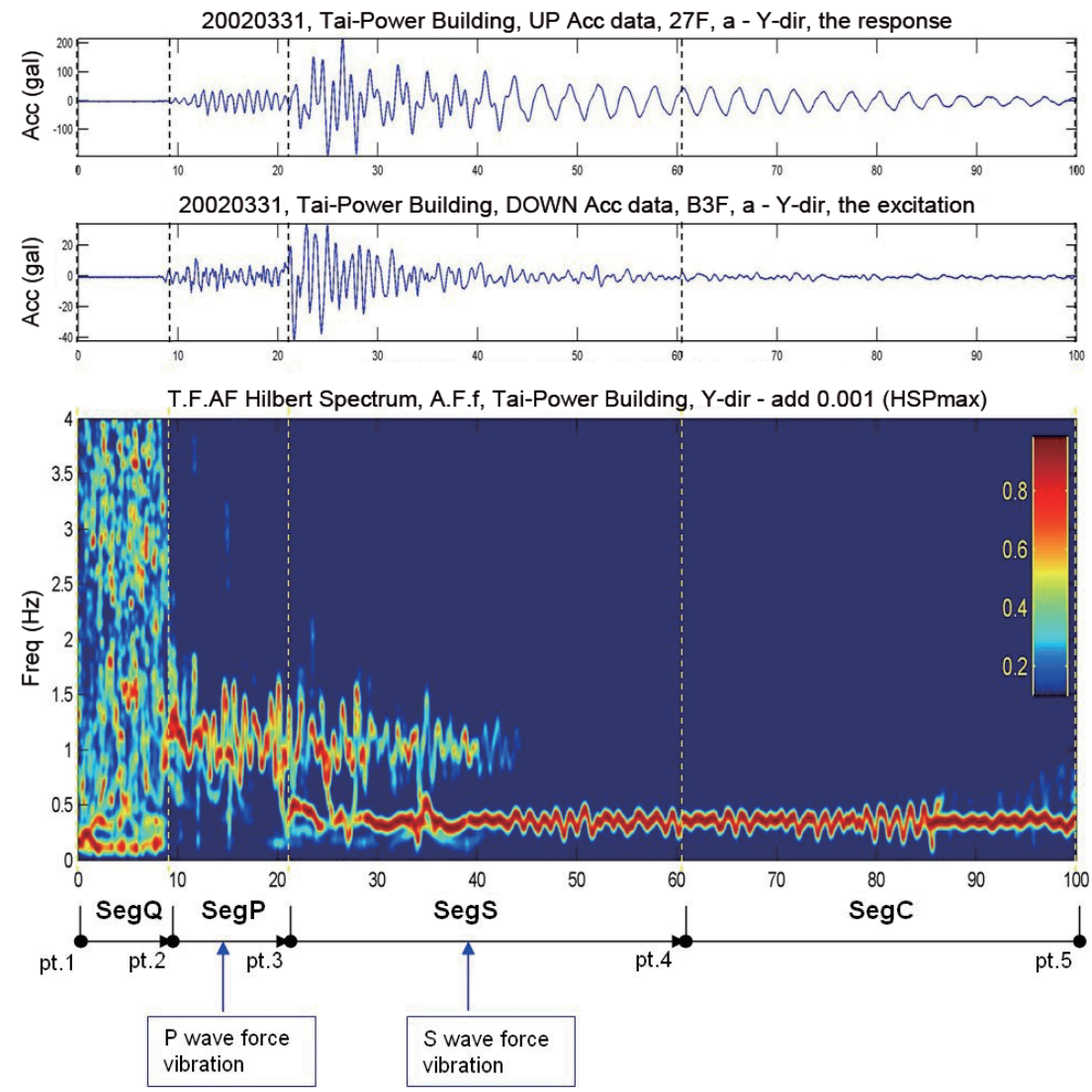

Fig. 9. A segmented strong-motion earthquake record and its 4 sub segments.

Note: Pt. 1: the start point of the record.

Pt. 2: the arrival time of earthquake P-wave, the result after waveform phase-picking.

$P t$. 3: the arrival time of earthquake $S$-wave, the result after waveform phase-picking.

Pt. 4: the starting of coda wave, this point is defined as the midpoint of pt.3 and 5.

Pt. 5: the end point of the record.

SegQ means the quiet sub segment of the strong-motion record, SegP means the P-wave sub segment, SegS means the S-wave sub segment, SegC means the Coda sub segment and SegA means the sum of all the sub segments.

T.F.AF in a precise and clear way. T.F.A.F. deserves more attention in future earthquake engineering applications.

The white noise is uniformly distributed in the spectrum with small amplitude and random phase. The appearance the white noise in the T.F.AF is shown on the SegQ in Fig. 9. Please remember the pattern, as it is commonly seen on the A.F.f.

Summing up sections 4.2.2 and 4.2.3, we demonstrated that the energy density and frequency variation information can be clearly determined by T.F.AFs. Furthermore, the temporal information can help us extract additional useful SHM parameters to be discussed presently. In next paragraph we will introduce another novel technique involving tracing the temporal variation in T.F.AF with CFR and WNF. The starting and ending point of the modal temporal curve will be determined by the mode behavior itself. Physically speaking, by identifying the structural feature, the structural modal behaviors (the MTVC) are extracted and determined from the wave-propagating properties (the T.F.AFs).

\subsection{Temporal Variations of Modal Dynamic Parameters (MTVC)}

We computed the CFR(t) of each mode to extract useful modal dynamic structural information from the T.F.AF. The band range for each mode should be set before the calculation. For the main building: $1^{\text {st }}$ mode: $0.15-0.50 \mathrm{~Hz}, 2^{\text {nd }}$ mode: $0.50-1.45 \mathrm{~Hz}$, and $3^{\text {rd }}$ mode: $1.45-2.40 \mathrm{~Hz}$. For the auxiliary building: $1^{\text {st }}$ mode: $0.50-1.50 \mathrm{~Hz}$, and $2^{\text {nd }}$ mode: $1.50-5.50 \mathrm{~Hz}$. The detailed steps are shown in Fig. 10, a demonstration of the MTVC extraction steps from the T.F.AF. Using CFR(t) and WNF we can obtain the MTVC result of the dominate frequency. Using the same band and the same start/end points as the dominate frequency MTVC we can obtain the MTVC result of the modal energy.

The MTVCs physically depict the dynamic responses of the building under the earthquake. The modal behavior of the building is calculated from the wave-propagating results. The original high nonlinear and nonstationary earthquake 
(a)
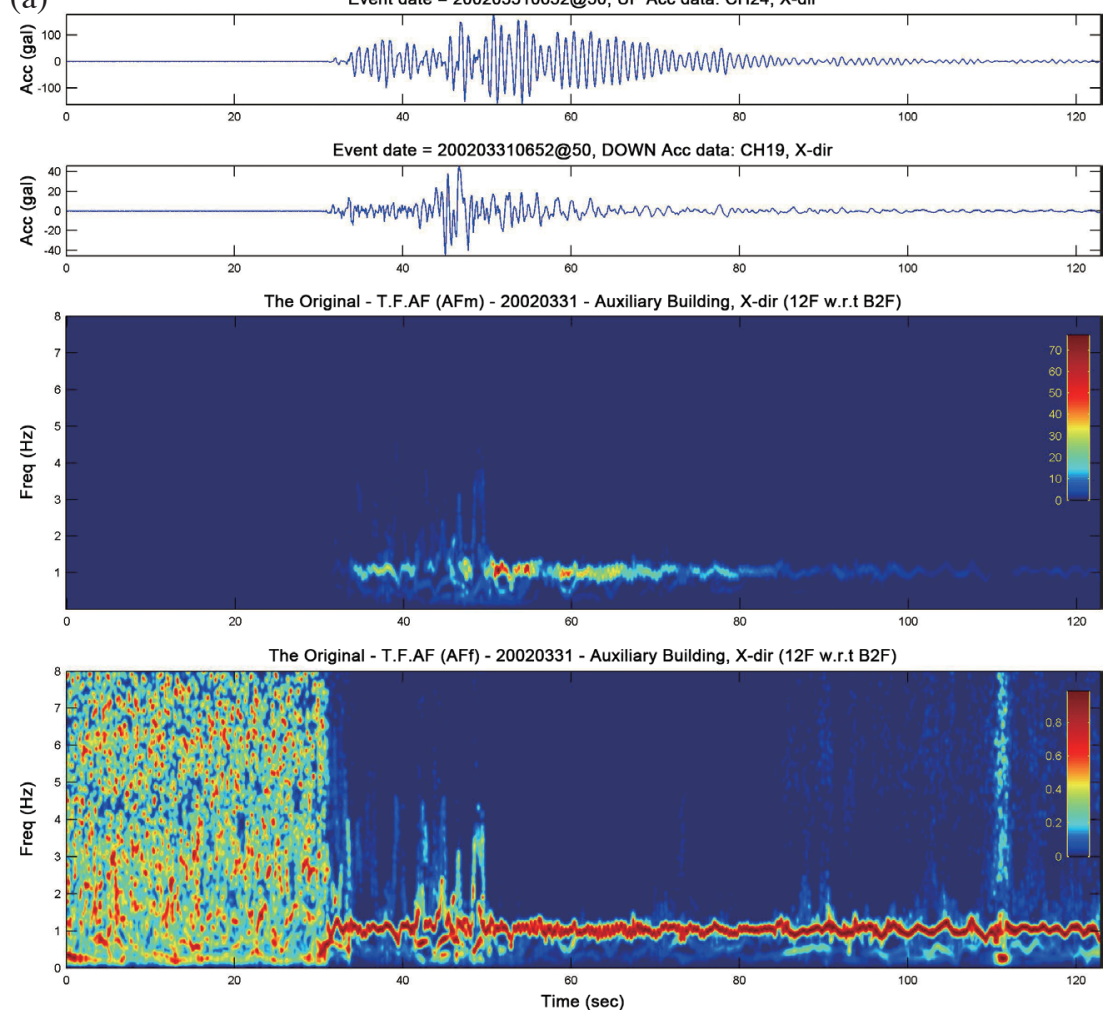

(b)
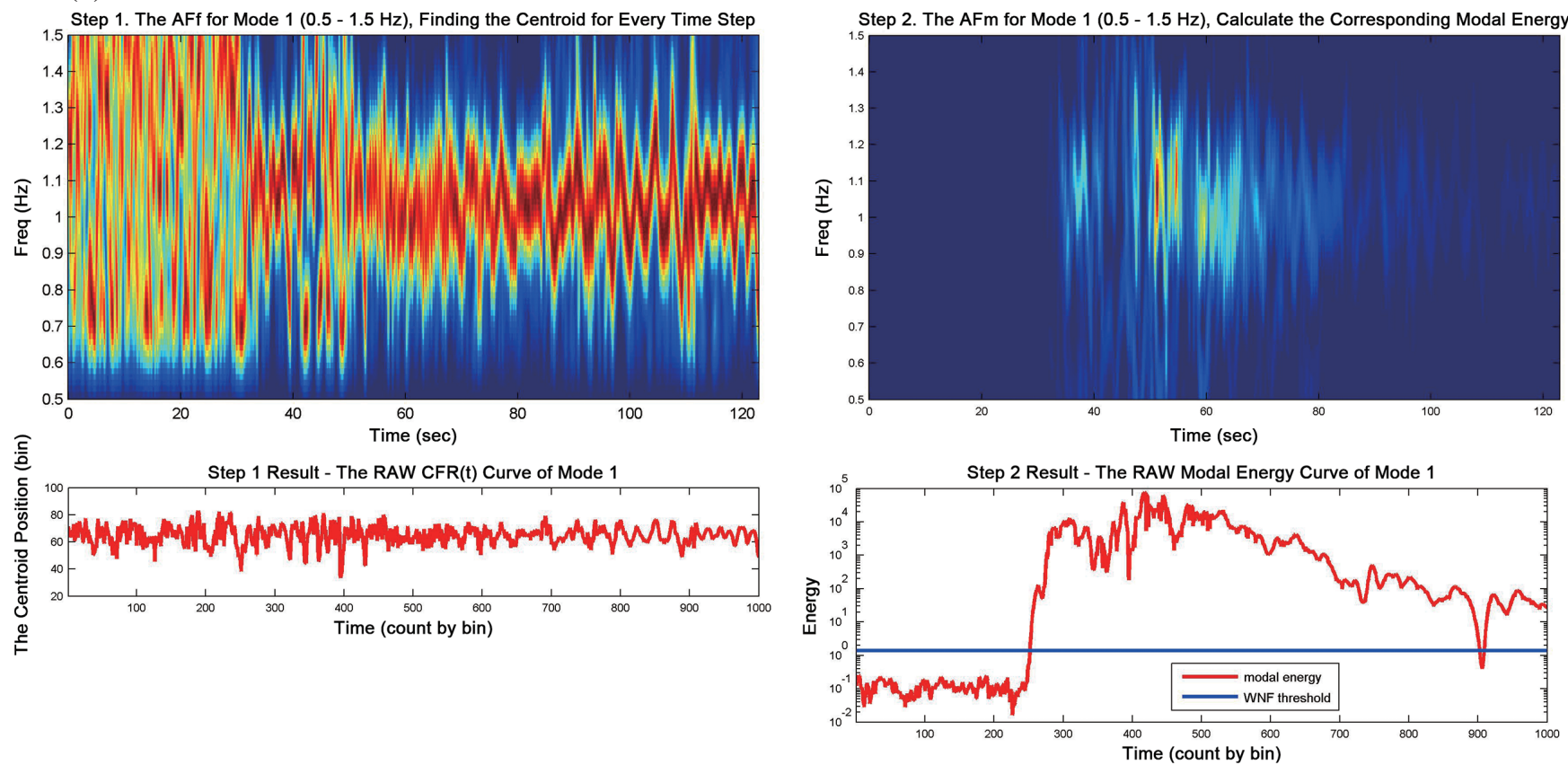

Fig. 10. (a) A demonstration of the digitize steps for the MTVC (1. the T.F.AF HSPs). (b) A demonstration of the digitize steps for the MTVC (step 1 and 2). (c) A demonstration of the digitize steps for the MTVC (step 3). Step 1: the dominate frequency MTVCs are made of the T.F.AF HSP (A.F.f). The instantaneous frequency information on the HSP is calculated for its Centroid in specific bandwidth of each mode. The raw CFR(t) curve is obtained (the red line of step1 result on the Fig. 10b). Step 2: using the same band as the A.F.f, now we compute the modal energy from the A.F.m HSP (the red line of step2 result on the Fig. 10b). Compare the background noise of this mode, than set the WNF threshold (the blue line of step2 result on the Fig. 10b). There is an intersection point for the red and blue lines. We assume the mode is been started after the intersection point. Step 3: remove the beginning white-noise signal out from the raw CFR $(\mathrm{t})$ curve, the modal variation behaviors are shown on the dominate frequency MTVC clearly. The modal energy MTVC is having the same start point of the frequency MTVC.

Note: Using the Tai-Power auxiliary building as our example is highly applicable for HHT SHM method testifying validation. The building is 12 floors height and the fundamental mode always appears during the earthquake excitation. The data from the auxiliary building is better than main building ones. For the main building data, there are three modes appear in the main building response. The fundamental mode signal frequently disappears during the earthquake. 

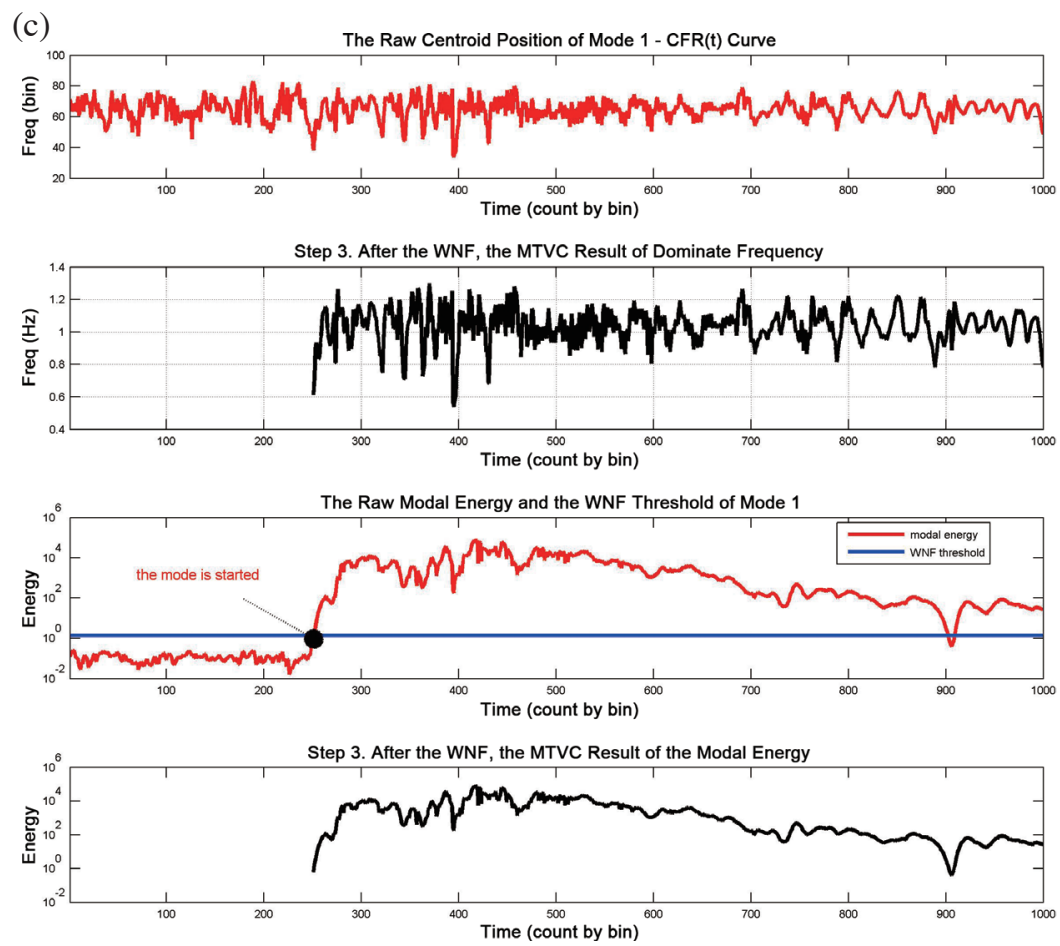

Fig. 10. (Continued)

signal was first transferred into the wave-propagating properties (the T.F.AF), and then some useful structural modal information (the MTVC) was extracted from the T.F.AF. Physically and mathematically the MTVCs are totally different from the original strong-motion building response waveforms. Structural or mechanical calculation is suitable to demonstrate the intrinsic MTVC characteristics. The impact on the structural elements for the earthquake load should be explored with the corresponding MTVCs of that event.

\section{THE ANALYSIS RESULTS}

The analysis results will also be the verifying results for the new HHT SHM analysis method. The T.F.AF results show all of the features during the wave-propagation. The MTVC results show the modal dynamic behaviors.

\subsection{The Dynamic Behavior of the SDOF Structure (Sinusoid Wave Excitation)}

The transient structural responses at the starting and ending moment during the experiment are the validation highlights. The gradual and sudden dynamic responses can be observed clearly using the T.F.A.F. All of the SDOF responses can also be computed from the theoretical mathematical solution.

The SDOF structures started the vibration from the cease condition to the full amplitude of the excitation sinusoid wave. The pounding behaviors occurred during the experiment, with the driving power then shutting down. The whole shaking-table gradually vibrated freely to the cease condition. For the T.F.A.F. of the entire experiment please see Fig. 11. Figures 11 - 13 are T.F.AF - A.F.f made form $0-5 \mathrm{~Hz}$ for the whole experiment, including the starting moment and ending moment.

The 0 - 3.6 s T.F.A.F. segment was fully-filled with ambient tiny noise. This is the appearance of the white-noise signal, the uniform frequency distribution on the spectrum. The same situations are also found in Figs. 9, 11 - 12, 14. At the starting stage the structure dominate frequency gradually increases and suddenly ceases while the sinusoid exciting frequency gradually increases, please see Fig. 12. The thin dotted line labels the dominate frequency position of the SDOF structure. The free-vibration at the end of the experiment was also interesting as the frequency suddenly jumped from the sinusoid exciting frequency into the structure dominate frequency. An unstable status about the moment is shown on the T.F.AF, please see Fig. 13.

The complicated wave-propagation characteristics of the SDOF structure from the T.F.AF - A.F.f were compared with analytical solution (Chopra 1995) here. Equations (13) and (14) show the governing equation and solution for the SDOF system to harmonic force. $P_{0}$ and $\omega$ are the amplitude and frequency of the forcing sinusoid. $\xi$ and $\omega_{n}$ are the damping ratio and natural frequency of the SDOF structure. The natural frequency for the undamped vibration system $\omega_{n}=\sqrt{k / m}$ and for the damped vibration system $\omega_{D}=\omega_{n} \sqrt{1-\xi^{2}}$. The coefficients $A$ and $B$ are the homogeneous solutions for the 
differential equation concerned with the initial condition $u(0)$ and $\dot{u}(0)$. For Eqs. (15) and (16) the coefficients $C$ and $D$ are the particular solutions for the differential equation for the steady state concerned with the forcing sinusoid function.

$m \ddot{u}+c \dot{u}+k u=P_{0} \sin \omega t$

$u(t)=e^{-\xi \omega_{n} t}\left(A \cos \omega_{D}+B \sin \omega_{D} t\right)+$ $(C \sin \omega t+D \cos \omega t)$

$C=\frac{P_{0}}{k} \frac{1-\left(\omega / \omega_{n}\right)^{2}}{\left[1-\left(\omega / \omega_{n}\right)^{2}\right]^{2}+\left[2 \xi\left(\omega / \omega_{n}\right)\right]^{2}}$

$$
D=\frac{P_{0}}{k} \frac{-2 \xi\left(\omega / \omega_{n}\right)}{\left[1-\left(\omega / \omega_{n}\right)^{2}\right]^{2}+\left[2 \xi\left(\omega / \omega_{n}\right)\right]^{2}}
$$

The solution can be decomposed into two parts; the first parenthesis is the transient and the second parenthesis is the steady. The steady part vibrates at the forcing frequency. The transient part vibrates at the dominate frequency of the SDOF structure within the decaying amplitude.

There should be two different frequencies simultaneously at the starting moment on the T.F.AF - A.F.f. We divided the A.F.f (for $3.6-9.0 \mathrm{~s}$ ) from $0-6 \mathrm{~Hz}$ into two sub bands: $2-6 \mathrm{~Hz}$ (the first) and $0-2 \mathrm{~Hz}$ (the second). The
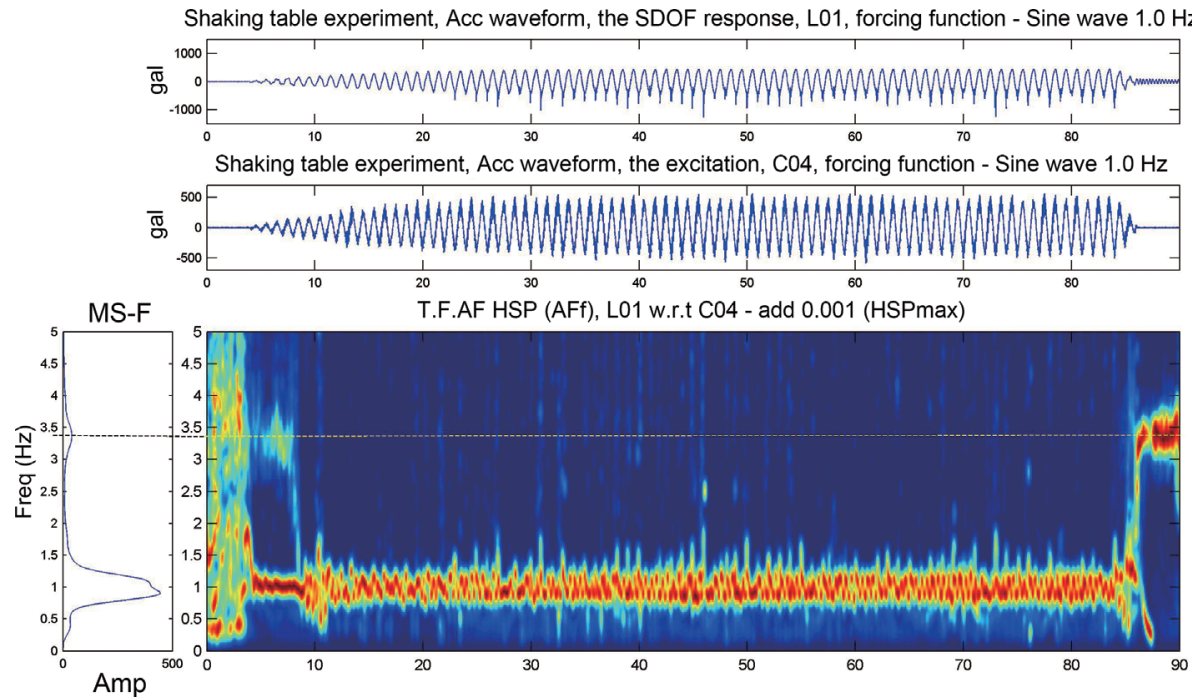

Fig. 11. T.F.AF HSP (A.F.f)-the dominate frequency of SDOF experiment results.

Note: There is an additional line located at $3.4 \mathrm{~Hz}$ on the spectrum, that is the dominate frequency of the SDOF structure L01. It helps to observe the result a lot.
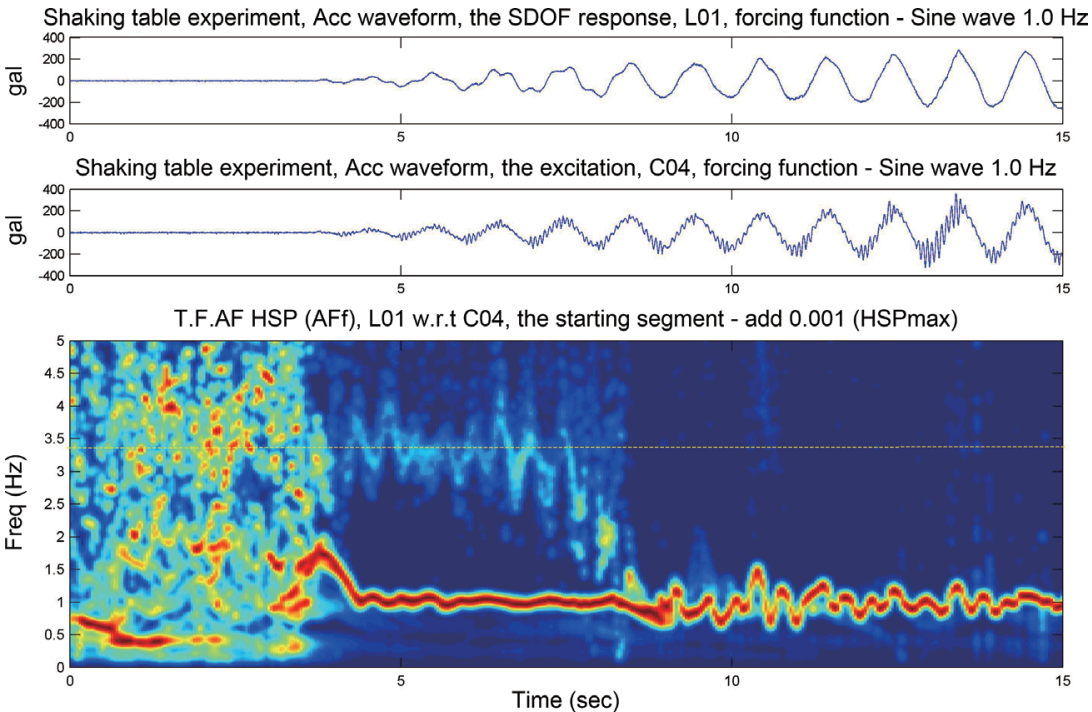

Fig. 12. T.F.AF HSP (A.F.f)-the dominate frequency of SDOF experiment results (T.F.AF examination result at the starting segment of the experiment). 

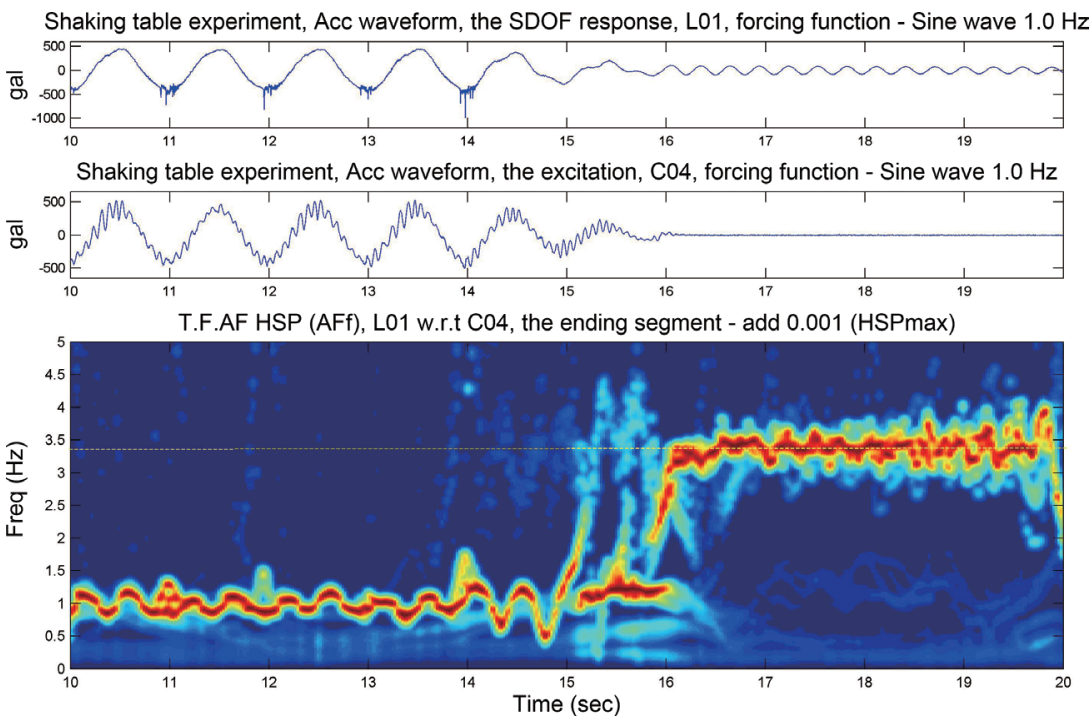

Fig. 13. T.F.AF HSP (A.F.f)-the dominate frequency of SDOF experiment results (T.F.AF examination result at the ending segment of the experiment).
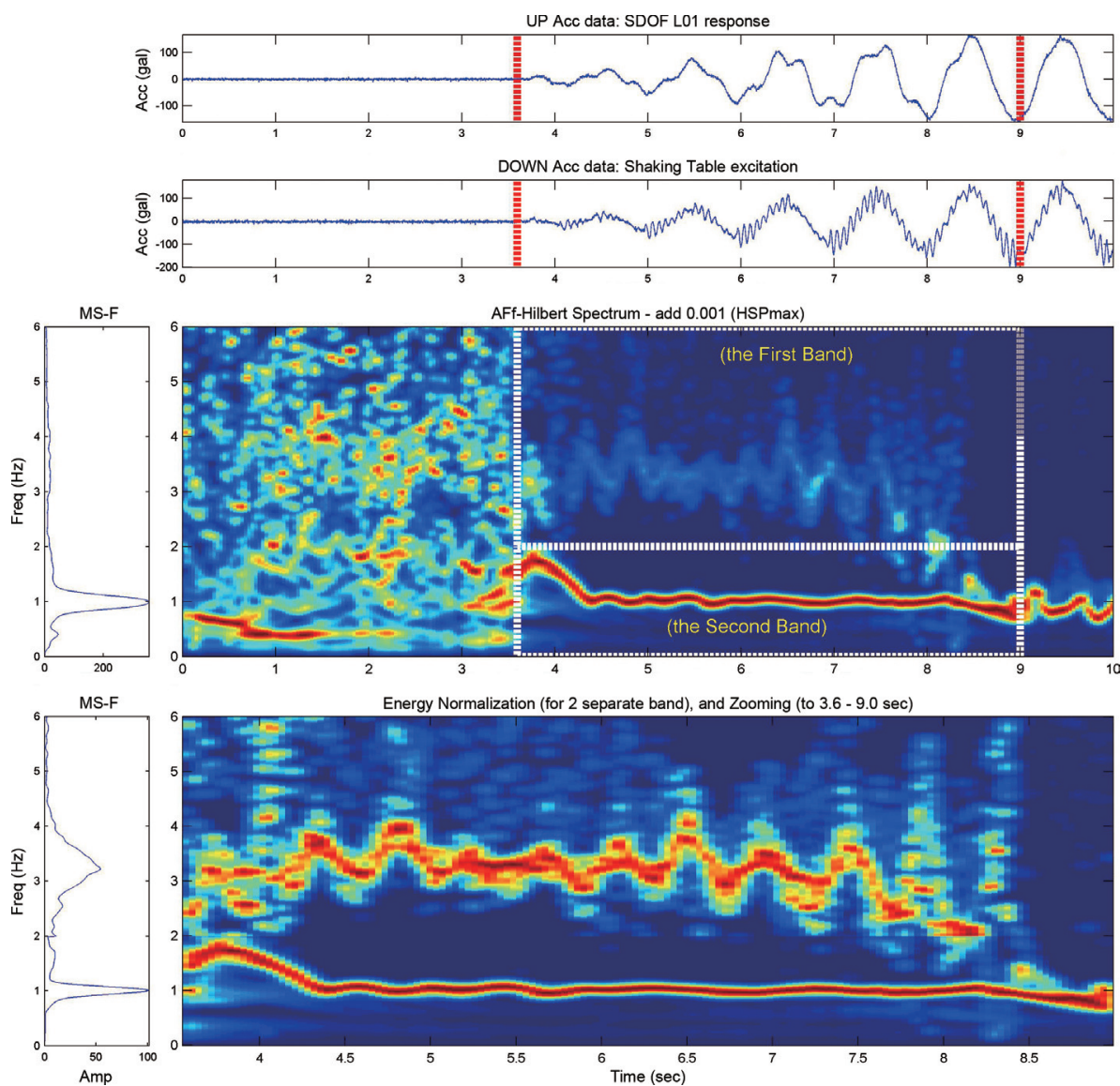

Fig. 14. The zooming range and result of A.F.f at the beginning for two separate band. 
instantaneous frequency and energy of each band are shown clearly and individually, please see Figs. 14 and 15. The SDOF wave-propagating details under sinusoid excitation are clearly shown and validated on the T.F.AFs. This is a convenient tool for identifying the dynamic vibration conditions. Useful SDOF structural modal clues can be extracted from some proportion of the T.F.AF.

When the pounding occurred both decks were shocked and vibrated at $1000 \mathrm{~Hz}$. Simultaneously, the impulse energy made the T.F.AF spike-like stripes (Figs. 11 and 16). Additionally, the SDOF excitation was the earthquake wave, please see the Fig. 17. The excitation frequency and the structure dominate frequency were mixed on the T.F.AF - A.F.f. during the $\mathrm{P}$ - and $\mathrm{S}$-wave phases. The wave-propagating details of the structure under the earthquake excitation are clearly shown on the T.F.AFs. The filtering and keeping behaviors are clearly shown. Useful structural modal information can be extracted from some proportion of the T.F.AF after correct judgments. The transient phenomenon of the analytical solution is clearly demonstrated on the T.F.AFs. The T.F.AF performance is clearly validated.

\subsection{The Tai-Power Building SHM Results 1994 - 2013}

The highlight in the Tai-Power building data is the appearance of improvement due to building reinforcement in the SHM performance results. New fluid viscous dampers (FVDs) were designed and installed in the main and auxiliary buildings, providing totally different structural performance. We can divide the SHM results into three different
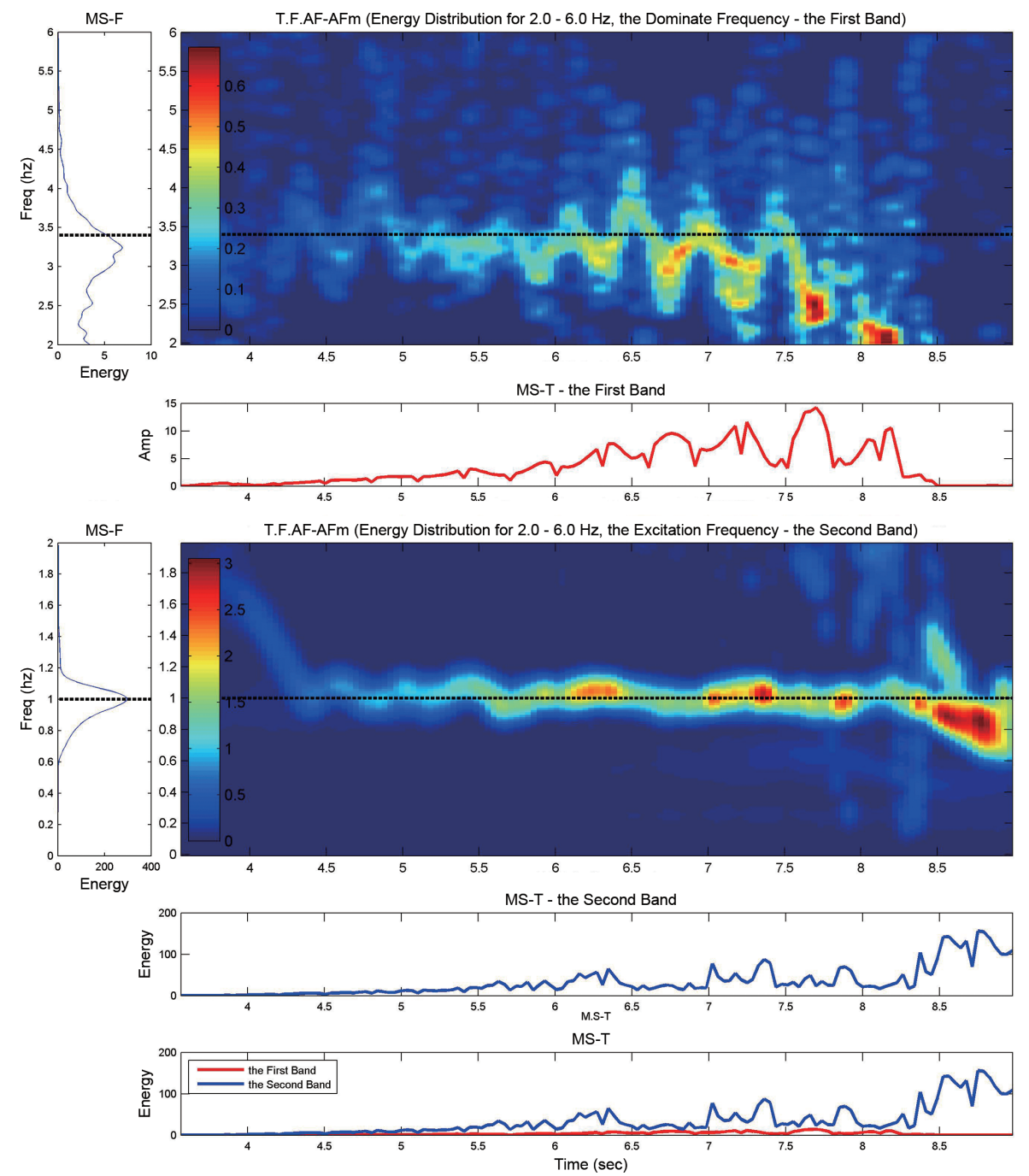

Fig. 15. The zooming result of A.F.m at the beginning (for two separate band).

Note: The Fig. 14 is the dominate frequency of the wave-propagation character under the sinusoid excitation. The energy is normalized for each band to show the instantaneous frequency for two bands. The existence of two different frequencies at the starting moment for a SDOF structure under sinusoid excitation is validated. The Fig. 15 is the energy of the each band of the wave-propagation character under the sinusoid excitation. The energy of first band is about $1-5 \%$ of the second band. All the details of the wave-propagation characteristics are kept on the HSP, with correct judgment and selection, the vivid differences can be shown clearly and precisely. 

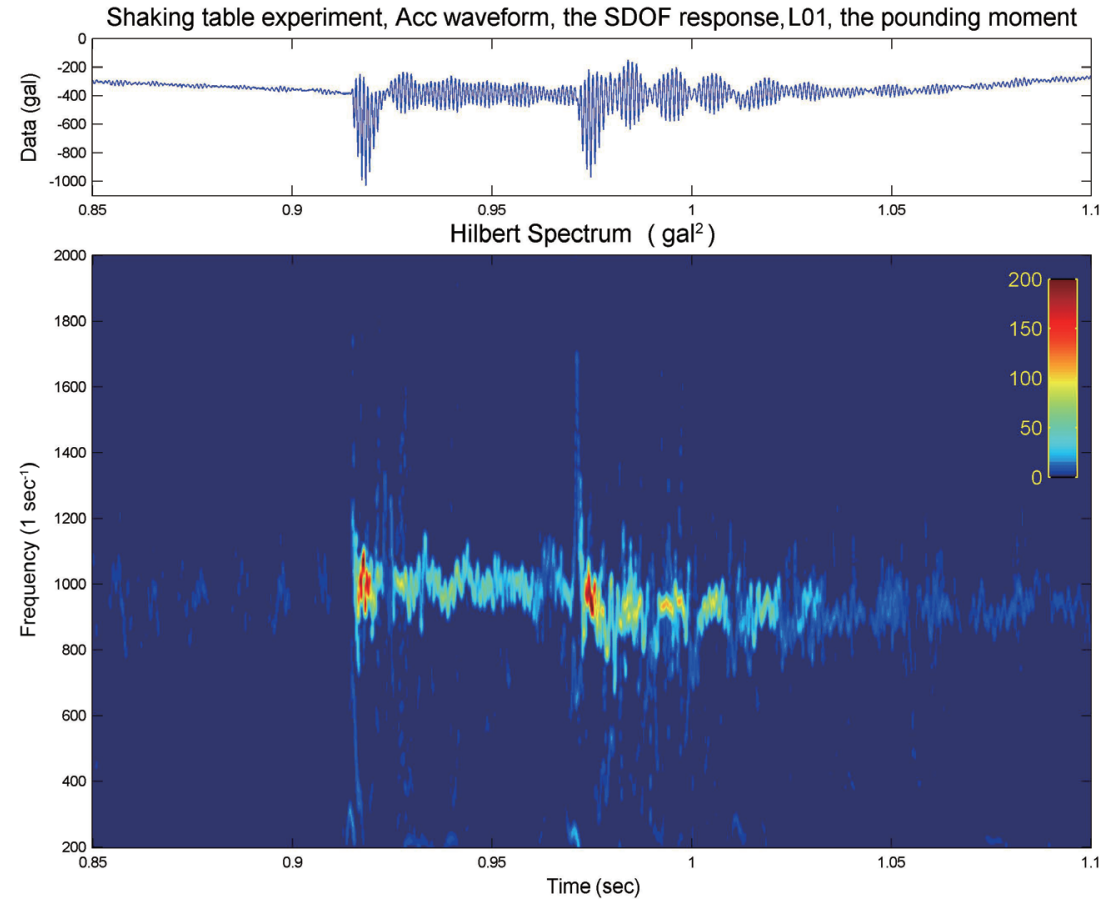

Fig. 16. The time-frequency spectrum at the pounding moment.

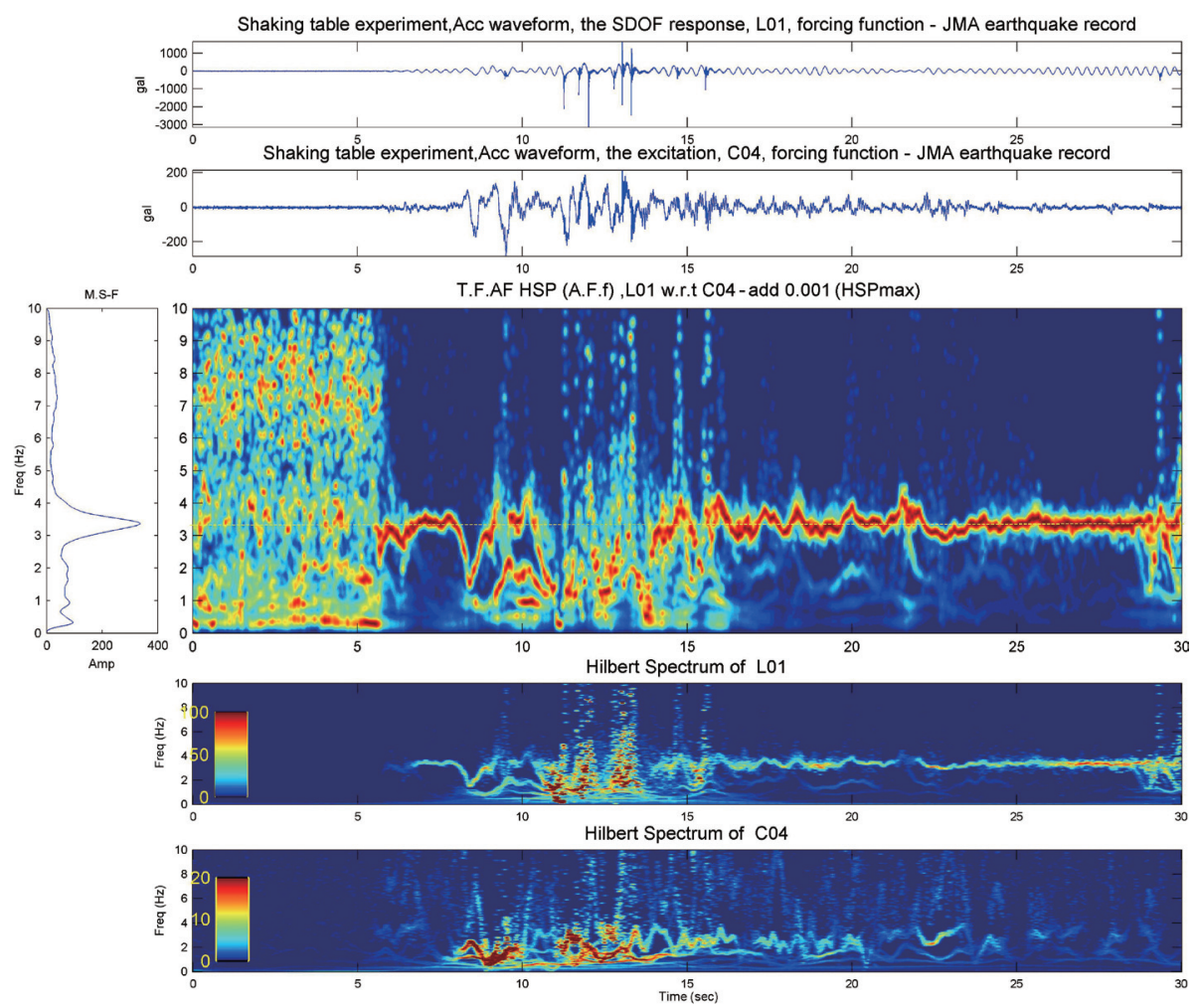

Fig. 17. The SDOF dynamic behavior under earthquake (shaking table experiment).

stages (the before-reinforcement stage, the reinforcement construction stage and the after-reinforcement stage, please see the Appendix).
With no structural reinforcing plan details we found a general introductory file of the plan on the Internet, please see Fig. 18. The buildings were well equipped with FVDs 
for better earthquake resistance performance. For instance 74 sets of FVDs were equipped in the original main building structure. The scheme was to lower the displacement and acceleration during shaking and change the original structural element in a slight way. The reinforcement plan was designed to increase the ductility and maintain the original mass/stiffness ratio. The compact installation of extra FVDs does help for a heavy use office building.

The reinforcement differences did help in discriminating the strengthened building from the original one. However, when we examined the T.F.AF of the Tai-Power Building records there were no apparent differences and no drastic drop in the natural frequency during excitation. Furthermore, lacking intact state information for comparison, evaluating a healthy structure about the SHM condition was quite hard work. With no apparent qualitative differences in the dominate frequency, seeking vivid statistical differences in the MTVCs from different events was the only practical quantitative way.

The II and NI were compared statistically to show the life time performance of the Tai-Power auxiliary building. Generally speaking, there were 155 events from 1994 - 2013 and the SHM indices were arranged in two ways (compared with channel maximum of absolute acceleration value and with the event date). Please see Figs. 19 - 22 for the SHM indices results for II-X-, II-Y-, NI-X-, and NI-Y-dir. Each figure shows the fifth floor and twelfth floor result in the upper and lower positions. The acceleration-related and date-related comparisons are arranged in the left half and the right half of the figure. The left half part shows the SHM index plotted with the channel acceleration value in a semilog plan. The right half shows the SHM index plotted with the event date. The date data is now presented in day units; please see the light thin yellow vertical lines for the date marks for January $1^{\text {st }}$ of 1996, 1999, 2002, 2005, 2008, and 2011 on the right half of Figs. 19 - 22. The three different data stages were represented using a cross mark, circle mark and triangle mark.

To show the relative differences in data the SHM indices were dimensionless first. The standard score (S.C) value is calculated using Eq. (17). The dimensionless data $S . C_{i}$ is calculated from the original data $X_{i}$. The $\mu$ is the mean of all the $X_{i}$ and the $\sigma$ is the standard deviation of all the $X_{i}$.

S.C. $=\frac{X_{i}-\mu}{\sigma}$

\section{Website information about the Tai-Power Building Structural Reinforcement Plan}

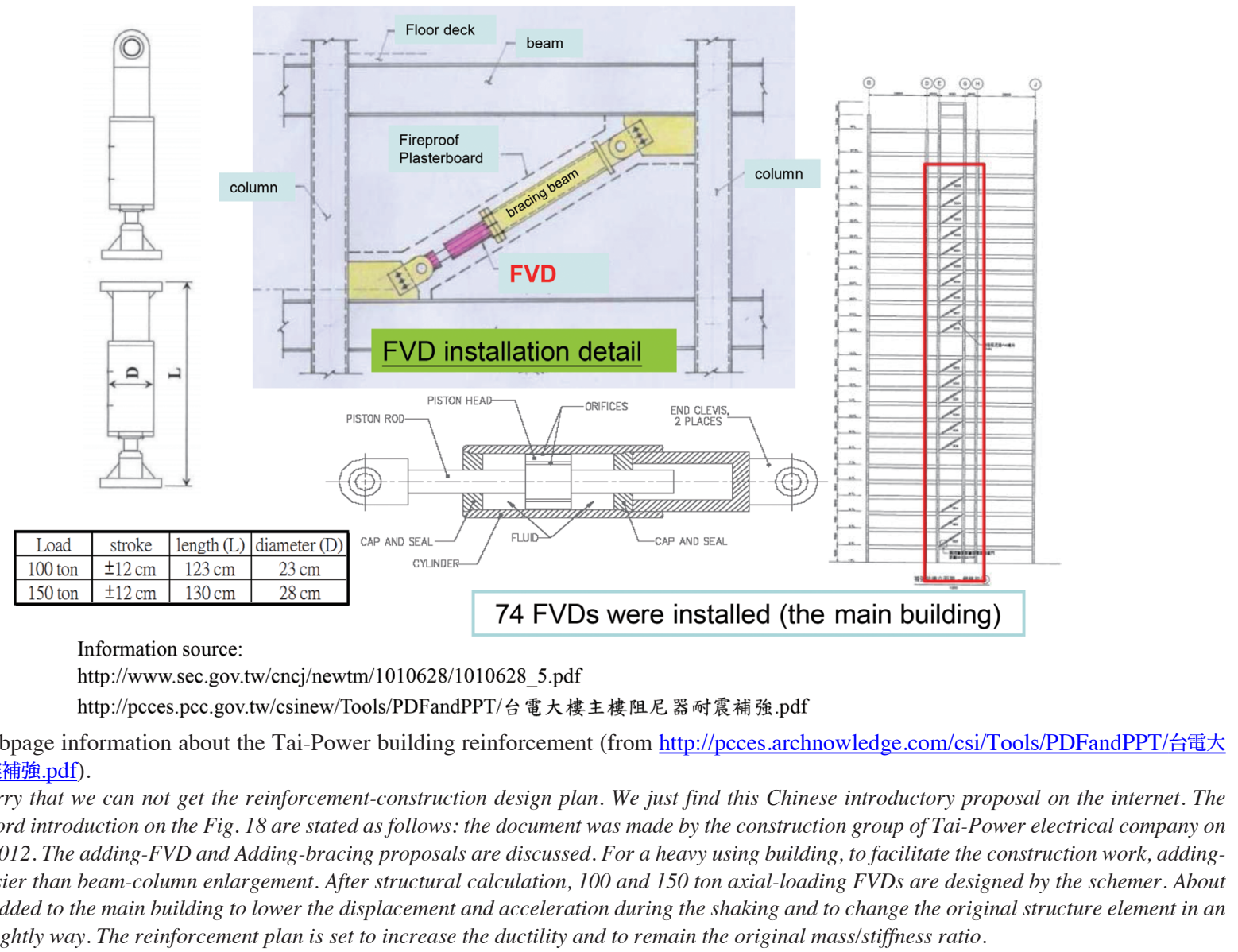

Fig. 18. The webpage information about the Tai-Power building reinforcement (from http://pcces.archnowledge.com/csi/Tools/PDFandPPT/台電大 樓主樓阻尼器耐震補強.pdf).

Note: We are sorry that we can not get the reinforcement-construction design plan. We just find this Chinese introductory proposal on the internet. The Chinese word introduction on the Fig. 18 are stated as follows: the document was made by the construction group of Tai-Power electrical company on July 31 ${ }^{\text {st }}$,2012. The adding-FVD and Adding-bracing proposals are discussed. For a heavy using building, to facilitate the construction work, addingFVD is easier than beam-column enlargement. After structural calculation, 100 and 150 ton axial-loading FVDs are designed by the schemer. About 74 FVDs added to the main building to lower the displacement and acceleration during the shaking and to change the original structure element in an extreme slightly way. The reinforcement plan is set to increase the ductility and to remain the original mass/stiffness ratio. 


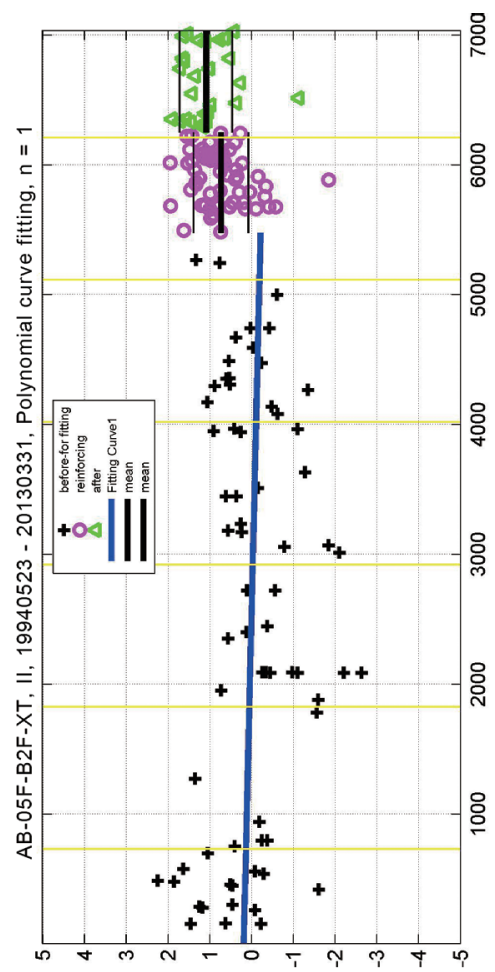

(әرoos pjepuets) әnjen J.S
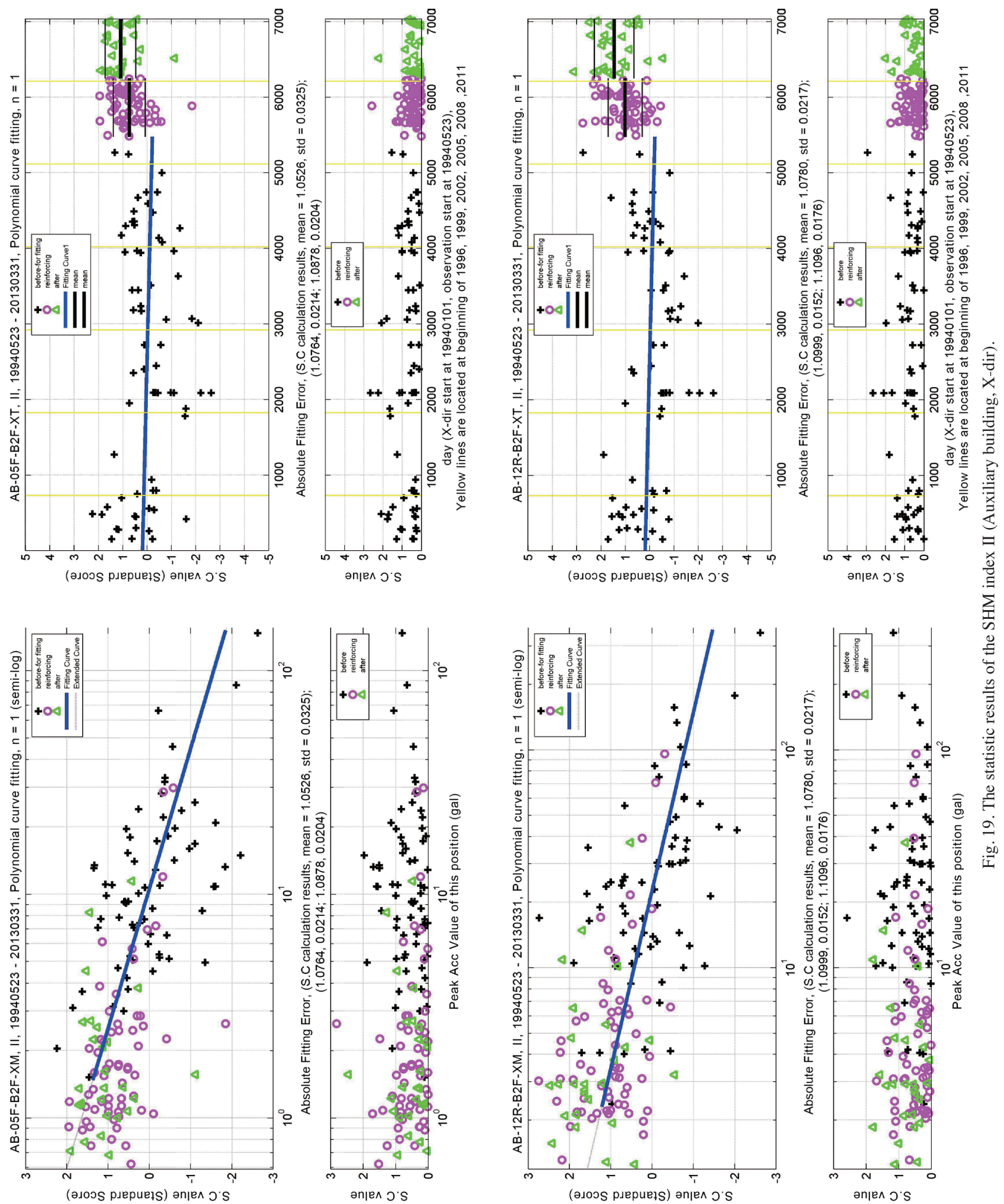


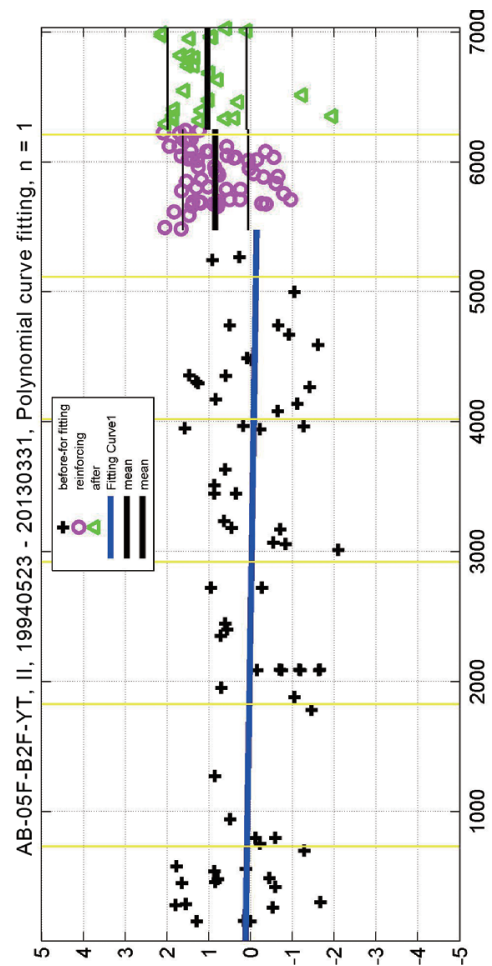

(әлоэS pıepuets) әпןе J.S
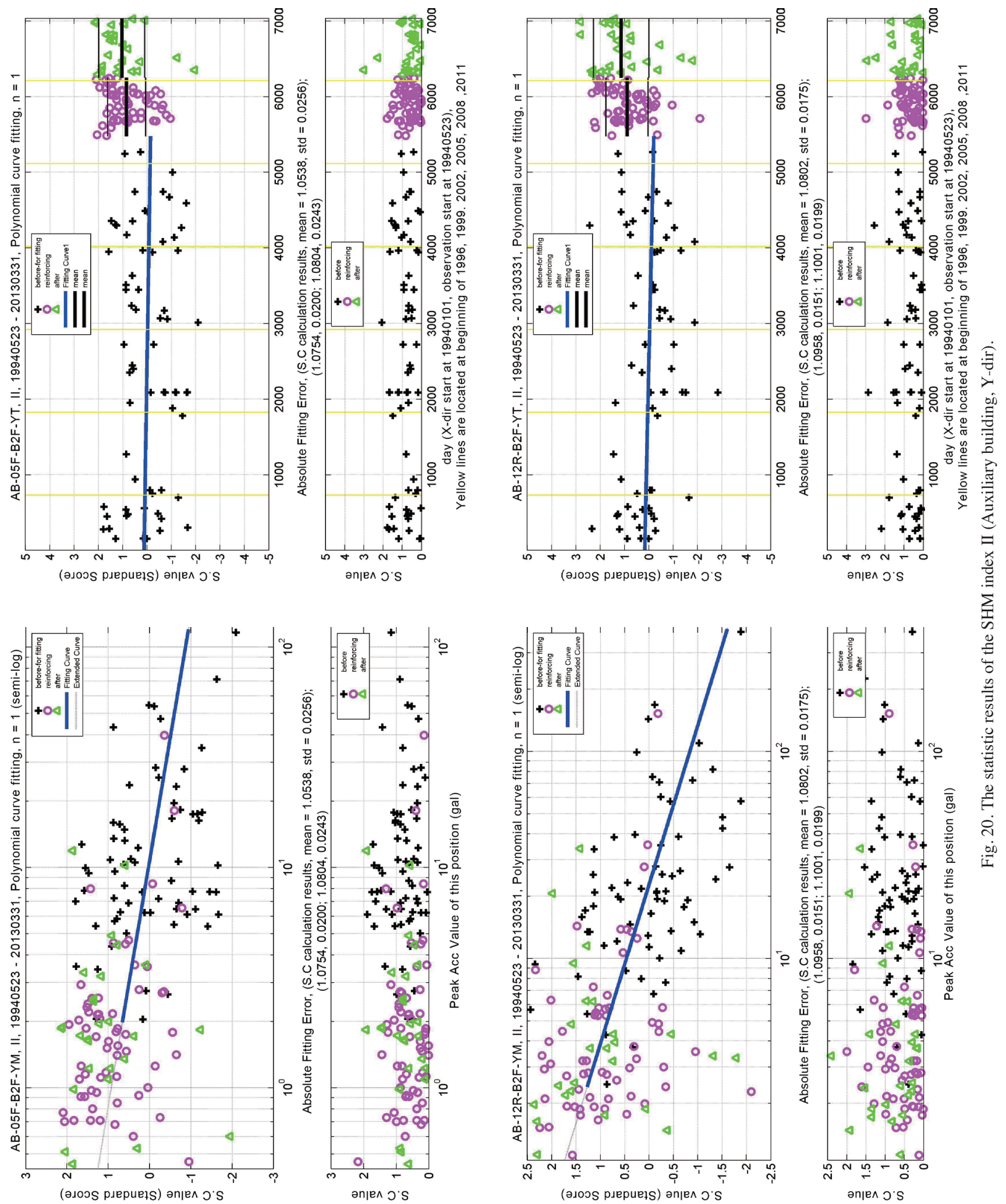

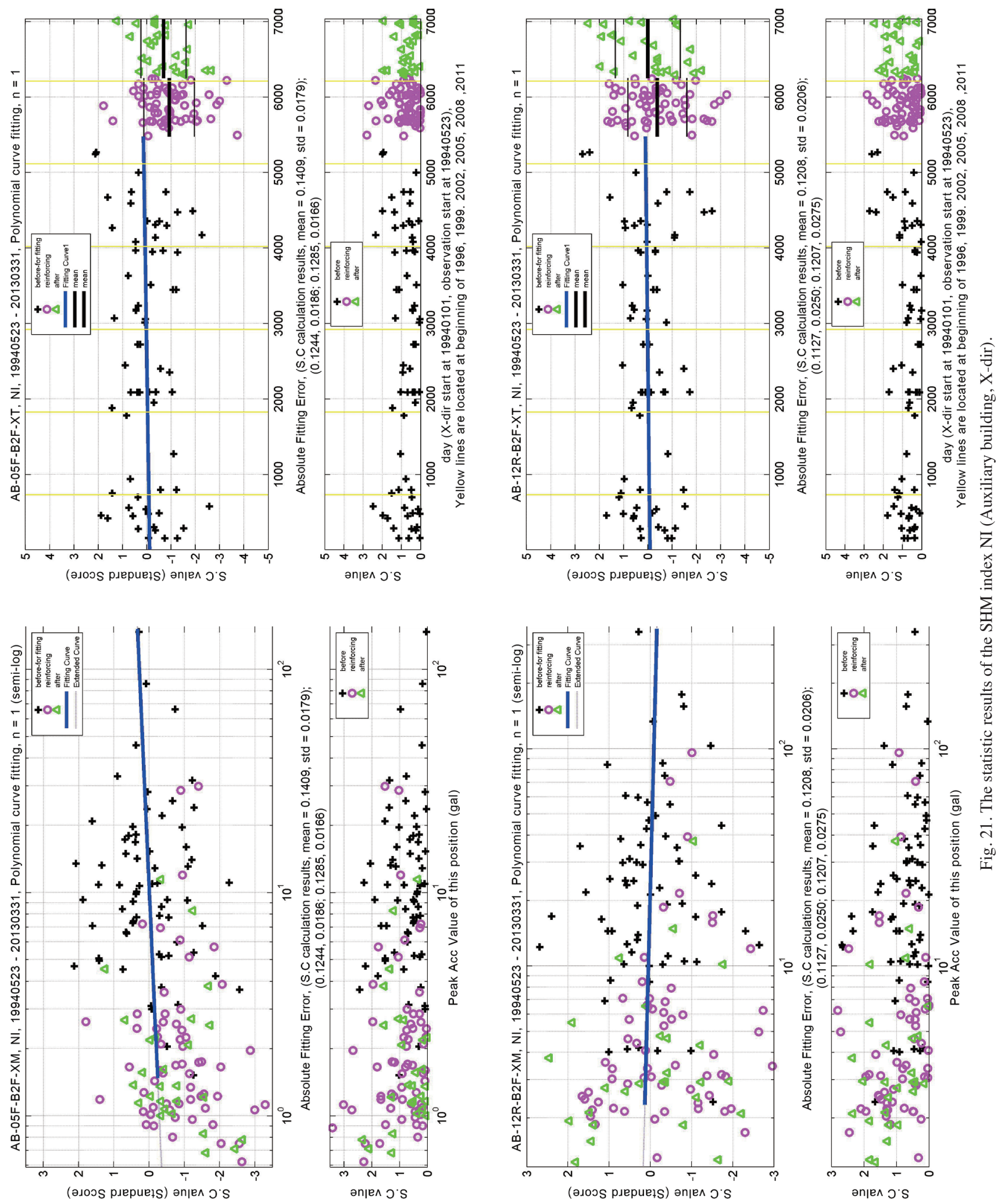

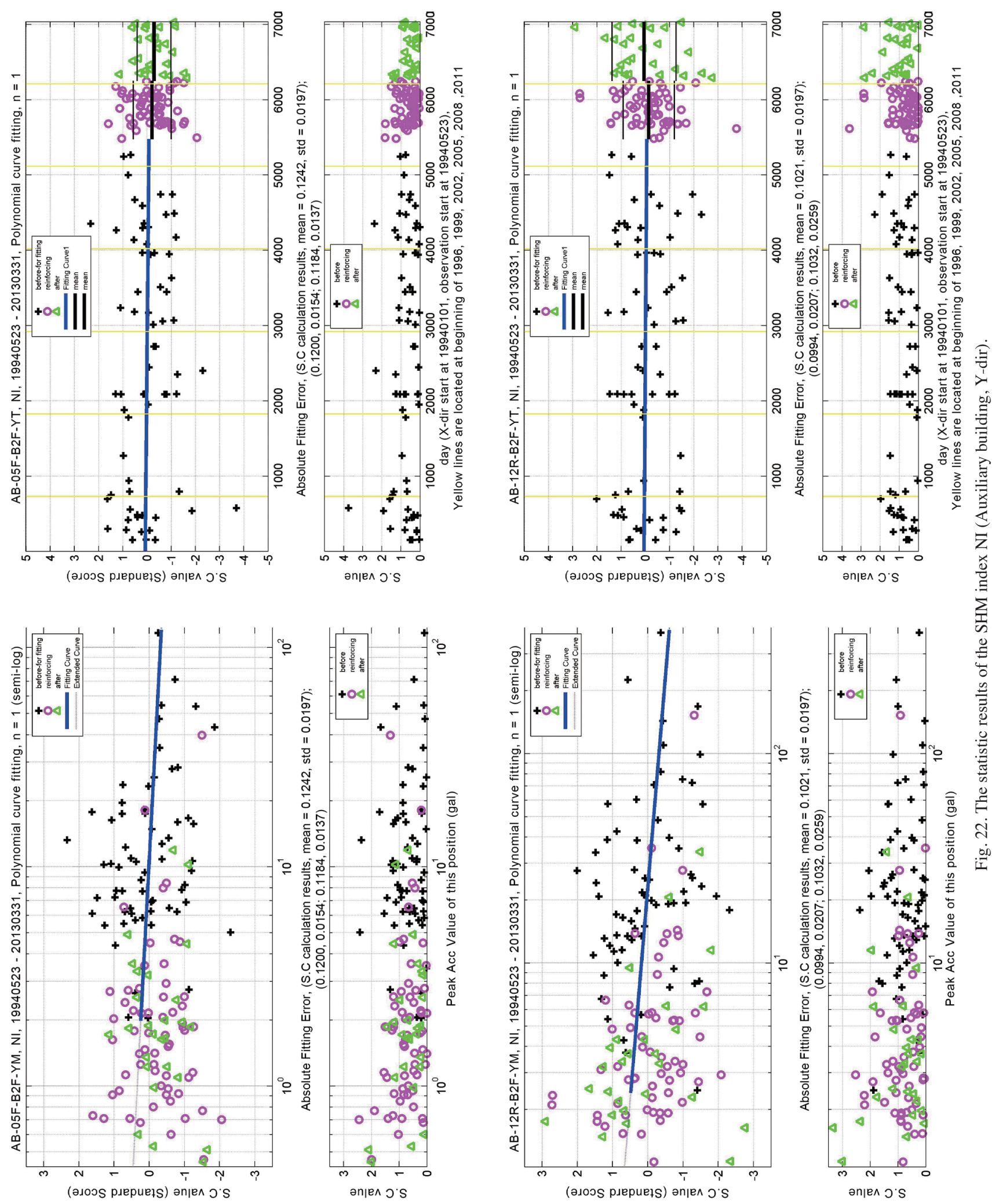
There is a linear fitting blue solid line plotted in the figure. It is calculated from the before-reinforcement stage data group. There are two extra short horizontal solid lines and four thin lines plotted on the right half of the figure. These are the mean and mean \pm std lines for the after-reinforcement and reinforcement-construction stage data groups. The mean and standard deviation values of the three different data groups are put together in Table 1 and Fig. 23.

From the upper half of Fig. 23 the II index shows an increasing tendency for 3 different stages. By definition the II is the mean temporal dominate frequency of the structure, the indicator of stiffness. The statistical result of II shows the dominate frequency of a healthy structure varying in a small range. This result is similar to earlier results (Bradford et al. 2006; Clinton et al. 2006). We also identified the health condition from the right half part of Figs. 19 and 20. The linear fitting blue solid lines of II of the 5F-X-, 12F-X-, 5F-Y-, and 12F-Y-dir are very flat for the period $1994-2008$. The short horizontal mean line of the reinforcement-construction stage and after-reinforcement stage data groups showed the structural intrinsic differences form the extra FVD elements during 2009 - 2013. The increment of frequency is about $0.02-0.03 \mathrm{~Hz}$. Briefly concluding, the structure is healthy during 1994 - 2008. The additional FVD-reinforcement

Table 1. Statistics of 155 events, the SHM indices.

\begin{tabular}{|c|c|c|c|c|c|c|c|c|c|}
\hline \multicolumn{10}{|c|}{ Statistics of 155 events, 1994 - 2013, Tai-Power Building Station, The Auxiliary Building } \\
\hline \multirow{2}{*}{ direction } & \multicolumn{2}{|c|}{ Structure Reinforcement } & \multicolumn{3}{|c|}{$12 F$} & \multicolumn{3}{|c|}{$05 \mathrm{~F}$} & \multirow{2}{*}{ unit } \\
\hline & Index & statistics & Before & Working & After & Before & Working & After & \\
\hline \multirow{4}{*}{ X-dir } & Integrity Index & mean & 1.0780 & 1.0999 & 1.1096 & 1.0526 & 1.0764 & 1.0878 & $(\mathrm{~Hz})$ \\
\hline & Integrity Index & std & 0.0217 & 0.0152 & 0.0176 & 0.0325 & 0.0214 & 0.0204 & $(\mathrm{~Hz})$ \\
\hline & Nonlinearity Index & mean & 0.1208 & 0.1127 & 0.1207 & 0.1409 & 0.1244 & 0.1285 & $(\mathrm{~Hz})$ \\
\hline & Nonlinearity Index & std & 0.0206 & 0.0250 & 0.0275 & 0.0179 & 0.0186 & 0.0166 & $(\mathrm{~Hz})$ \\
\hline \multirow{4}{*}{ Y-dir } & Integrity Index & mean & 1.0802 & 1.0958 & 1.1001 & 1.0538 & 1.0754 & 1.0804 & $(\mathrm{~Hz})$ \\
\hline & Integrity Index & std & 0.0175 & 0.0151 & 0.0199 & 0.0256 & 0.0200 & 0.0243 & $(\mathrm{~Hz})$ \\
\hline & Nonlinearity Index & mean & 0.1021 & 0.0994 & 0.1032 & 0.1242 & 0.1200 & 0.1184 & $(\mathrm{~Hz})$ \\
\hline & Nonlinearity Index & std & 0.0197 & 0.0207 & 0.0259 & 0.0197 & 0.0154 & 0.0137 & $(\mathrm{~Hz})$ \\
\hline
\end{tabular}
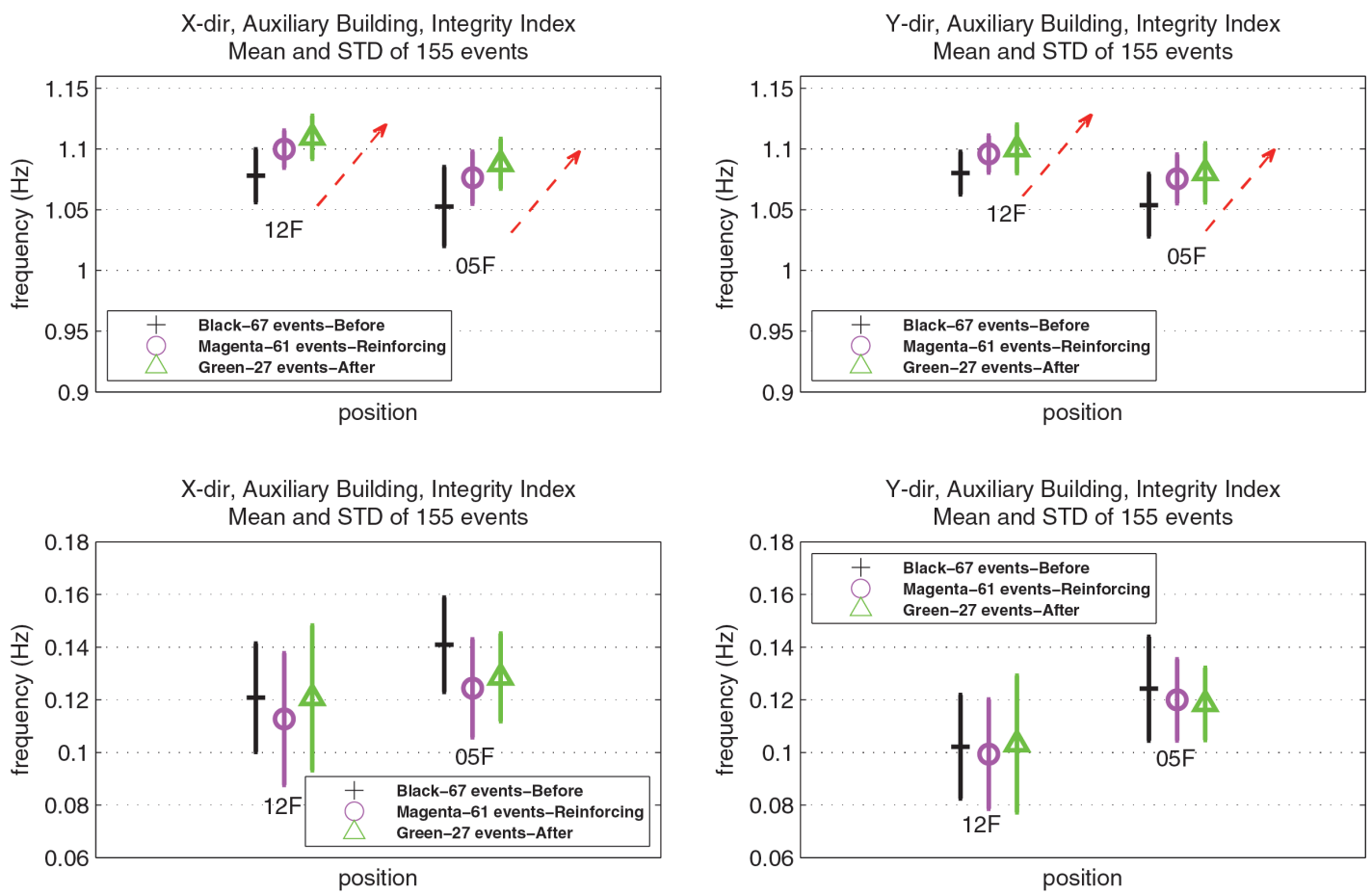

Fig. 23. The statistic result of SHM indices of Auxiliary Building for 155 events. 
strengthened the building in a slightly way as planned.

The dominate frequency value of a healthy structure is not constant, it is variant within a specific small range and the variation corresponds to the forcing condition. We can see the left half part of Figs. 19 and 20. The II index becomes smaller while the acceleration maximum value becomes larger. The linear fitting blue solid lines of II of the 5F-X-, 12F-X-, $5 \mathrm{~F}-\mathrm{Y}-$, and $12 \mathrm{~F}-\mathrm{Y}$-dir are telling us the same tendency.

The NI used here is very similar to the one introduced by Huang et al. (2013), but our result is based on the Hilbert Spectral representation. Although the definition here is less rigorous it is accurate enough more practical approach for engineering applications. To explain the new concept visually we plotted the Fig. 24 to show the character of the NI. There were two signals:the wave A is the unit amplitude sinusoid $1 \mathrm{~Hz}$ wave with surrounding white-noise $(0.1 \%$ random signal, zero mean), the wave B is wave A plus structural nonlinearity (30\% random signal, zero mean). We assume that a healthy structure acts like wave $\mathrm{A}$, the vibration is smooth. While a slightly damaged structure will act like wave $\mathrm{B}$, the vibration is not smooth (please see the right lower small figure in Fig. 24). We assume the nonlinearity phenomena might be the beginning of subtle damage. From
Fig. 24 the HSP of wave A and wave B are quite different. We can judge the difference by the width of the MS-F (please see the left lower small figure in Fig. 24). A slightly damaged structure will have a MTVC result with serious perturbation. The NI is designed to detect the small differences in the SHM index.

From the lower half of Fig. 23 the NI index results are not so consistent with the II results for three stages. We find that the NI values become smaller during the reinforcementconstruction stage. It is hard to conclude a clear tendency for NI. This might be because the Tai-Power building is still in a healthy condition or because the new CWB data-logging system collected a lot of small events during 2009 - 2013.

\section{DISCUSSIONS AND CONCLUSIONS}

The response frequency is intrinsic to the structure and the squared vibration frequency value is proportional to the structural stiffness. We can use the frequency values relative to a reference value (say, at the new and intact condition of the building) to calculate the quantitative loss of structural integrity as in railway bridge engineering practice (Zhang et al. 2005). The drastic frequency drop in the forced object
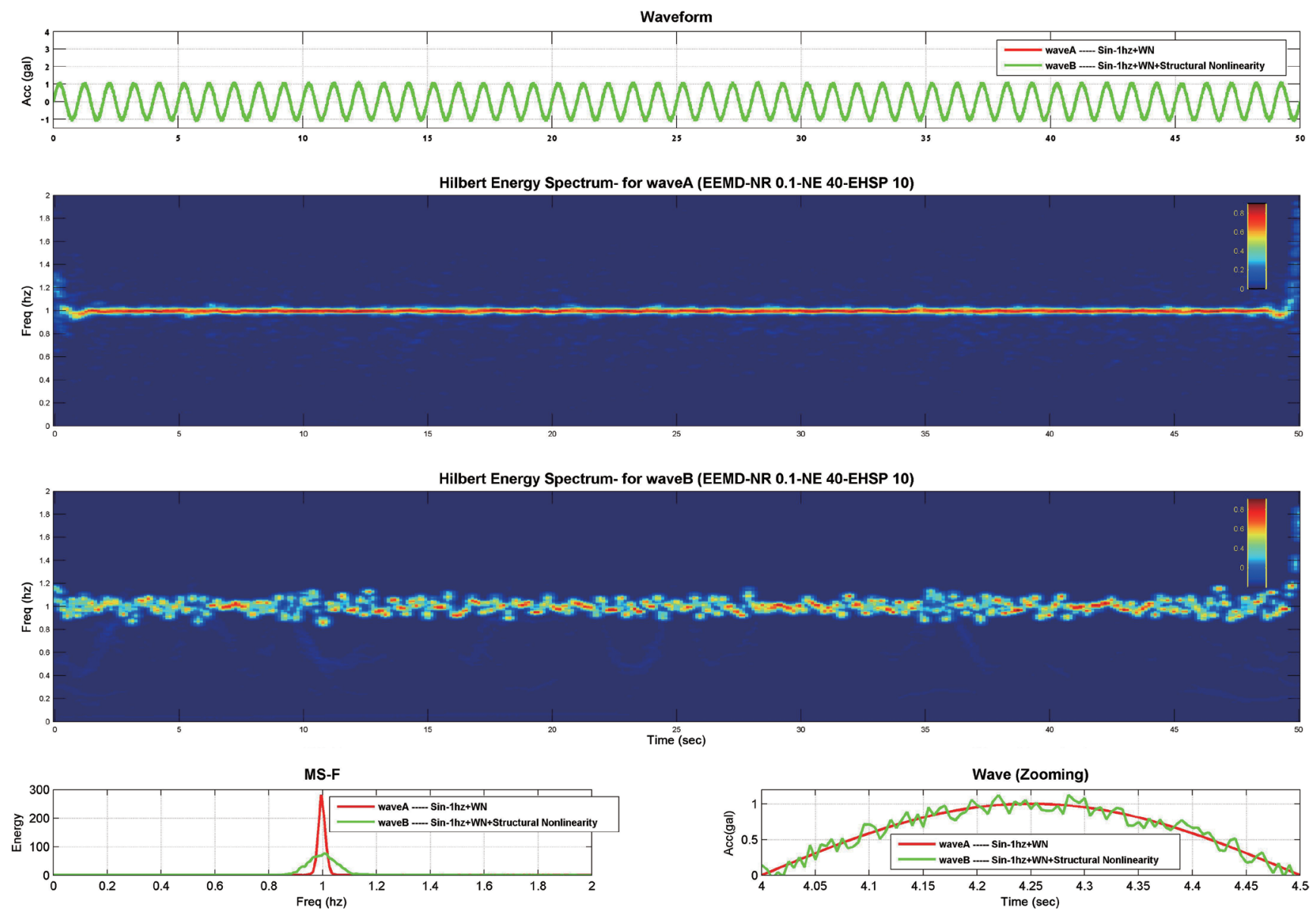

Fig. 24. The physical meaning of the structural nonlinearity. 
indicates serious structural softening, frequently accompanied with structural damage. It should be noted that a drastic decrease in the modal frequency, many times the value observed in the Tai-Power building, could be an indicator of severe structural damage. Fortunately, for this case the building is still healthy. The result from the new HHT SHM method can still give useful information for the judgmentmaking engineer.

The data-logging instruments of the CWB strongmotion system were replaced at the end of the 2008. The new computer and data-logging system help collect vivid building earthquake responses. There were 67 records during $1994-2008(67 / 14=4.8$ event per year $)$ and 88 records during $2009-2013(88 / 4.3=20.5$ event per year). We can read the small earthquake results on the left half part of the Figs. 19 - 22. The abundance of data helped a lot in our method validation. For small earthquake events the surrounding noise is harder to remove. The weak modal energy is mixed with surrounding noise. The NI index was originally designed to observe the vivid differences in the dominate frequency. This might also be the reason that we could not find a definite tendency in the NI results.

The most frequent vibration-based SHM approach is "Comparing the Relative Differences!" Researchers are finding structural-mechanical related parameters as the detecting indicator from the in situ vibration records. To coincide with the theoretical modal dominate frequency numerical and mathematical methodologies are applied to the earthquake excitation response. Unfortunately, in calculating the earthquake spectrum the important mathematical and physical restrictions are usually totally ignored because there is no adequate alternative to Fourier analysis. The earthquake frequency responses are averaged over all different phases of the waveform. As an earthquake is patently nonstationary (Huang et al. 2001), additionally for strong earthquakes, the forcing function could be highly nonlinear as well. Therefore, it is imperative to adopt an adequate alternative method for analyzing the building response in a time-frequency fashion.

The present approach is precisely such an alternative. By reading the dominate frequency directly and finding the amplification relationship on the time-frequency domain HSP all dynamic behavior during the excitation is clearly shown on the temporal axis. The high resolution and high precision T.F.AF is the most valuable core for this new method. Tracing clues in both time and frequency domain on the instantaneous structure dominate frequency statistically makes the SHM work easily and directly. With the Hilbert Transform prowess the energy density and instantaneous frequency can be calculated precisely and correctly. After adequate selection and mechanical judgment the useful structural modal information can be extracted from the T.F.AF.

Although the building is still in healthy condition the new approach could still provide needed dynamic param- eters. The new approach reveals much more than these simple dynamic parameters; it clearly depicts the dynamic processes in the temporal history in minute detail. Our method can examine the vivid differences and give a complete evolutionary history report about the building health condition.

In additional to facilitating physical understanding of the structural dynamics, the new approach also introduces a new SHM method. Various SHM methods based on HHT have been introduced before ( $\mathrm{Li}$ et al. 2003; Huang et al. 2005). The present study has added another call for action. More testifying and validating work should be arranged, for instance, a Multiple-Degree-Of-Freedom (MDOF) shakingtable experiment is urgently expected for further understanding about the Tai-Power building.

Temporal perturbations of the dynamic structural signals are critical information for nonlinear and nonstationary studies. Exploring useful SHM information from real building records is the new key to this exciting work. The vivid differences in structural healthy condition could be explored by examining these MTVCs. The proposed approach is a highly applicable method for dynamic system and SHM observations.

Acknowledgements We used data from TSMIP-BA system of the Central Weather Bureau. The Taiwan Power Company is the property owner of the Tai-Power building. This article also used data from shaking-table experiments conducted by Professor Tzu-Ying Lee, civil engineering department, National Central University. We thank them for their contribution of valuable records for this study. This study also was supported by the National Science Council under Grant No. NSC102-2116-M-008-023.

\section{REFERENCES}

Borcherdt, R. D., 1970: Effects of local geology on ground motion near San Francisco Bay. Bull. Seismol. Soc. Am., 60, 29-61.

Bradford, S. C., J. Yang, and T. Heaton, 2006: Variations in the Dynamic Properties of Structures: The Wigner-Ville Distribution. Proceedings of the $8^{\text {th }}$ U.S. National Conference on Earthquake Engineering, April 18-22, San Francisco, California, USA, Paper No.1439, 10 pp.

Chopra, A. K., 1995: Dynamics of Structures: Theory and Applications to Earthquake Engineering, PrenticeHall, Englewood Cliffs, NJ, 444-452.

Clinton, J. F., S. C. Bradford, T. H. Heaton, and J. Favela, 2006: The observed wander of the natural frequencies in a structure. Bull. Seismol. Soc. Am., 96, 237-257, doi: 10.1785/0120050052. [Link]

Huang, N. E., C. C. Chern, K. Huang, L. W. Salvino, S. R. Long, and K. L. Fan, 2001: A new spectral representation of earthquake data: Hilbert spectral analysis of station TCU129, Chi-Chi, Taiwan, 21 September 1999. Bull. Seismol. Soc. Am., 91, 1310-1338, doi: 
10.1785/0120000735. [Link]

Huang, N. E., Z. Shen, S. R. Long, M. C. Wu, H. H. Shih, Q.Zheng, N.C. Yen, C. C. Tung, and H. H. Liu, 1998: The empirical mode decomposition and the Hilbert spectrum for nonlinear and non-stationary time series analysis. Proc. R. Soc. Lond. A, 454, 903-995, doi: 10.1098/rspa.1998.0193. [Link]

Huang, N. E., K. Huang, and W. L. Chiang, 2005: HHTbased bridge structural health-monitoring method. Hilbert-Huang Transform and its Applications, World Scientific Pub, Chapter 12.

Huang, N. E., M. J. Brenner, and L. Salvino, 2006: HilbertHuang transform stability spectral analysis applied to flutter flight test data. AIAA J., 44, 772-786, doi: 10.2514/1.11501. [Link]

Huang, N. E., M. T. Lo, Z. H. Wu, and X. Y. Chen, 2013: Method for quantifying and modeling degree of nonlinearity, combined nonlinearity, and nonstationarity. United States Patent Application, Assigneet: National Central University, Jhongli City, Taiwan, Pub. No.: US 2013/0080378 A1.

Lee, T. Y. and K. J. Chung, 2012: Experimental and analytical study on the pounding effect of bridges with inclined decks. Proceedings of the $15^{\text {th }}$ World Confer- ence on Earthquake Engineering, Lisbon, Portugal, Paper No. 3254.

Li, Y. F., S. Y. Chang, W. C. Tzeng, and K. Huang, 2003: The pseudo dynamic test of RC bridge columns analyzed through the Hilbert-Huang transform. J. Mech., 19, 373-387, doi: 10.1017/S1727719100003221. [Link]

Wen, K. L., H. Y. Peng, Y. B. Tsai, and K. C. Chen, 2001: Why $1 G$ was recorded at TCU129 site during the 1999 Chi-Chi, Taiwan, earthquake? Bull. Seismol. Soc. Am., 91, 1255-1266, doi: 10.1785/0120000707. [Link]

Wu, Z. and N. E. Huang, 2004: A study of the characteristics of white noise using the empirical mode decomposition method. Proc. R. Soc. Lond. A, 460, 1597-1611, doi: 10.1098/rspa.2003.1221. [Link]

Wu, Z. and N. E Huang, 2009: Ensemble Empirical Mode Decomposition: A noise-assisted data analysis method. Adv. Adapt. Data Anal., 1, 1-41, doi: 10.1142/ S1793536909000047. [Link]

Zhang, R. R., R. King, L. Olson, and Y. L. Xu, 2005: Dynamic response of the Trinity River Relief Bridge to controlled pile damage: Modeling and experimental data analysis comparing Fourier and Hilbert-Huang techniques. J. Sound Vib., 285, 1049-1070, doi: 10.1016/j.jsv.2004.09.032. [Link]

\section{APPENDIX: EARTHQUAKE CATALOGUE: NO.1 - 155}

\begin{tabular}{|c|c|c|c|c|c|c|c|c|c|c|c|c|c|c|c|c|}
\hline \multicolumn{17}{|c|}{ CWB Earthquake Catalogue for Tai-Power building station (TAPBA4) } \\
\hline 編號 & 年 & 月 & 日 & 時 & 分 & 秒 & & 韋度 & & 度 & 深度 & 規模 & 震央距 & 震源距 & 主機 & 結構補強 \\
\hline \multirow{2}{*}{ No. } & year & month & day & hour & $\min$ & sec & & itude & lon & itude & depth & \multirow{2}{*}{ ML } & km & km & \multirow{2}{*}{$\begin{array}{l}\text { logging } \\
\text { system }\end{array}$} & \multirow{2}{*}{$\begin{array}{c}\text { Structure } \\
\text { reinforcement }\end{array}$} \\
\hline & \multicolumn{6}{|c|}{ Event time(UTC) } & \multicolumn{5}{|c|}{ EQ location and depth } & & hypo-dist & epi-dist & & \\
\hline 1 & 1994 & 6 & 5 & 1 & 9 & 30.09 & 24 & 27.74 & 121 & 50.26 & 5.30 & 6.50 & 69.1 & 69.3 & DOS & before \\
\hline 2 & 1994 & 6 & 5 & 5 & 51 & 43.02 & 24 & 27.79 & 121 & 54.83 & 4.99 & 4.83 & 72.8 & 73.0 & DOS & before \\
\hline 3 & 1994 & 6 & 6 & 8 & 57 & 24.49 & 24 & 25.85 & 121 & 56.91 & 3.45 & 5.06 & 77.7 & 77.8 & DOS & before \\
\hline 4 & 1994 & 9 & 16 & 6 & 20 & 15.62 & 22 & 25.58 & 118 & 28.01 & 19.06 & 6.43 & 424.6 & 425.0 & DOS & before \\
\hline 5 & 1994 & 10 & 5 & 1 & 13 & 24.47 & 23 & 9.38 & 121 & 43.22 & 31.28 & 5.83 & 207.9 & 210.2 & DOS & before \\
\hline 6 & 1994 & 10 & 12 & 9 & 8 & 22.18 & 24 & 48.58 & 122 & 1.14 & 73.68 & 5.67 & 54.4 & 91.6 & DOS & before \\
\hline 7 & 1994 & 10 & 28 & 23 & 51 & 10.48 & 24 & 38.13 & 122 & 16.17 & 2.00 & 5.66 & 85.9 & 85.9 & DOS & before \\
\hline 8 & 1995 & 2 & 23 & 5 & 19 & 2.78 & 24 & 12.22 & 121 & 41.22 & 21.69 & 5.77 & 91.9 & 94.4 & DOS & before \\
\hline 9 & 1995 & 3 & 24 & 4 & 13 & 51.09 & 24 & 38.28 & 121 & 51.64 & 76.00 & 5.64 & 53.8 & 93.1 & DOS & before \\
\hline 10 & 1995 & 4 & 3 & 11 & 54 & 40.08 & 23 & 56.13 & 122 & 25.90 & 14.55 & 5.88 & 151.0 & 151.7 & DOS & before \\
\hline 11 & 1995 & 4 & 24 & 10 & 4 & 0.96 & 24 & 39.10 & 121 & 37.33 & 63.07 & 5.28 & 41.7 & 75.6 & DOS & before \\
\hline 12 & 1995 & 5 & 2 & 22 & 48 & 20.54 & 23 & 49.99 & 121 & 58.38 & 23.93 & 5.24 & 139.1 & 141.2 & DOS & before \\
\hline 13 & 1995 & 6 & 25 & 6 & 59 & 7.09 & 24 & 36.37 & 121 & 40.11 & 39.88 & 6.50 & 47.8 & 62.3 & DOS & before \\
\hline 14 & 1995 & 7 & 14 & 16 & 52 & 46.48 & 24 & 19.22 & 121 & 51.06 & 8.79 & 5.80 & 84.0 & 84.5 & DOS & before \\
\hline 15 & 1995 & 7 & 30 & 18 & 0 & 52.96 & 25 & 9.93 & 121 & 34.94 & 5.23 & 3.05 & 17.3 & 18.0 & DOS & before \\
\hline 16 & 1995 & 12 & 1 & 3 & 17 & 4.62 & 24 & 36.36 & 121 & 38.56 & 45.07 & 5.72 & 47.1 & 65.2 & DOS & before \\
\hline 17 & 1996 & 1 & 22 & 19 & 22 & 57.53 & 24 & 55.70 & 121 & 43.42 & 66.86 & 5.11 & 21.9 & 70.3 & DOS & before \\
\hline 18 & 1996 & 3 & 5 & 14 & 52 & 27.13 & 23 & 55.81 & 122 & 21.69 & 6.00 & 6.40 & 147.3 & 147.4 & DOS & before \\
\hline
\end{tabular}


CWB Earthquake Catalogue for Tai-Power building station (TAPBA4)

\begin{tabular}{|c|c|c|c|c|c|c|c|c|c|c|c|c|c|c|c|c|}
\hline 編號 & 年 & 月 & 日 & 時 & 分 & 秒 & \multicolumn{2}{|c|}{ 緯度 } & \multicolumn{2}{|c|}{ 經度 } & 深度 & 規模 & 震央距 & 震源距 & 主機 & 結構補強 \\
\hline \multirow{2}{*}{ No. } & year & month & day & hour & $\min$ & sec & lat & itude & long & itude & depth & \multirow{2}{*}{ ML } & km & km & \multirow{2}{*}{$\begin{array}{l}\text { logging } \\
\text { system }\end{array}$} & \multirow{2}{*}{$\begin{array}{c}\text { Structure } \\
\text { reinforcement }\end{array}$} \\
\hline & \multicolumn{6}{|c|}{ Event time(UTC) } & \multicolumn{5}{|c|}{ EQ location and depth } & & hypo-dist & epi-dist & & \\
\hline 19 & 1996 & 3 & 5 & 17 & 32 & 8.56 & 23 & 53.91 & 122 & 18.18 & 10.81 & 5.96 & 147.0 & 147.4 & DOS & before \\
\hline 20 & 1996 & 7 & 29 & 20 & 20 & 53.53 & 24 & 29.33 & 122 & 20.82 & 65.68 & 6.14 & 101.3 & 120.7 & DOS & before \\
\hline 21 & 1997 & 6 & 24 & 16 & 37 & 12.89 & 25 & 7.18 & 121 & 34.79 & 8.55 & 3.70 & 12.4 & 15.1 & DOS & before \\
\hline 22 & 1998 & 11 & 17 & 22 & 27 & 32.52 & 22 & 49.93 & 120 & 47.42 & 16.49 & 5.51 & 254.4 & 254.9 & DOS & before \\
\hline 23 & 1999 & 2 & 22 & 13 & 48 & 58.05 & 23 & 58.50 & 122 & 39.27 & 4.21 & 5.90 & 162.4 & 162.5 & DOS & before \\
\hline 24 & 1999 & 5 & 7 & 1 & 3 & 24.41 & 24 & 44.33 & 121 & 53.53 & 4.17 & 5.44 & 47.9 & 48.1 & DOS & before \\
\hline 25 & 1999 & 9 & 20 & 17 & 47 & 15.85 & 23 & 51.15 & 120 & 48.93 & 8.00 & 7.30 & 148.4 & 148.6 & DOS & before \\
\hline 26 & 1999 & 9 & 20 & 17 & 57 & 15.58 & 23 & 54.70 & 121 & 2.66 & 7.68 & 6.44 & 132.4 & 132.7 & DOS & before \\
\hline 27 & 1999 & 9 & 20 & 18 & 11 & 54.21 & 23 & 51.89 & 121 & 4.03 & 12.49 & 6.70 & 136.5 & 137.0 & DOS & before \\
\hline 28 & 1999 & 9 & 20 & 18 & 16 & 17.95 & 23 & 51.69 & 121 & 2.45 & 12.53 & 6.66 & 137.8 & 138.3 & DOS & before \\
\hline 29 & 1999 & 9 & 20 & 21 & 46 & 38.11 & 23 & 35.08 & 120 & 51.42 & 8.57 & 6.59 & 173.3 & 173.5 & DOS & before \\
\hline 30 & 1999 & 9 & 22 & 0 & 14 & 40.77 & 23 & 49.58 & 121 & 2.80 & 15.59 & 6.80 & 141.2 & 142.1 & DOS & before \\
\hline 31 & 1999 & 9 & 22 & 0 & 49 & 43.45 & 23 & 45.88 & 121 & 1.88 & 17.38 & 6.20 & 148.2 & 149.2 & DOS & before \\
\hline 32 & 2000 & 6 & 10 & 18 & 23 & 29.45 & 23 & 54.06 & 121 & 6.55 & 16.21 & 6.70 & 131.3 & 132.3 & DOS & before \\
\hline 33 & 2000 & 7 & 28 & 20 & 28 & 7.72 & 23 & 24.66 & 120 & 55.96 & 7.35 & 6.10 & 188.6 & 188.8 & DOS & before \\
\hline 34 & 2000 & 9 & 10 & 8 & 54 & 46.53 & 24 & 5.12 & 121 & 35.03 & 17.74 & 6.20 & 103.8 & 105.3 & DOS & before \\
\hline 35 & 2001 & 6 & 13 & 13 & 17 & 54.15 & 24 & 22.87 & 122 & 36.39 & 64.41 & 6.25 & 129.7 & 144.8 & DOS & before \\
\hline 36 & 2001 & 6 & 14 & 2 & 35 & 25.78 & 24 & 25.13 & 121 & 55.68 & 17.29 & 6.30 & 77.8 & 79.7 & DOS & before \\
\hline 37 & 2002 & 3 & 31 & 6 & 52 & 49.95 & 24 & 8.39 & 122 & 11.49 & 13.81 & 6.80 & 118.3 & 119.1 & DOS & before \\
\hline 38 & 2002 & 5 & 15 & 3 & 46 & 5.91 & 24 & 39.06 & 121 & 52.31 & 8.52 & 6.20 & 53.4 & 54.1 & DOS & before \\
\hline 39 & 2002 & 5 & 28 & 16 & 45 & 14.97 & 23 & 54.78 & 122 & 23.81 & 15.23 & 6.20 & 150.9 & 151.7 & DOS & before \\
\hline 40 & 2002 & 9 & 7 & 22 & 59 & 32.85 & 24 & 26.86 & 121 & 41.32 & 41.36 & 5.26 & 65.4 & 77.3 & DOS & before \\
\hline 41 & 2002 & 9 & 16 & 0 & 3 & 30.74 & 25 & 6.09 & 122 & 23.25 & 175.67 & 6.80 & 86.9 & 196.0 & DOS & before \\
\hline 42 & 2002 & 11 & 10 & 0 & 7 & 4.98 & 24 & 53.36 & 121 & 50.56 & 110.27 & 5.42 & 34.6 & 115.6 & DOS & before \\
\hline 43 & 2003 & 6 & 9 & 1 & 52 & 50.57 & 24 & 22.22 & 122 & 1.40 & 23.22 & 5.72 & 87.5 & 90.6 & DOS & before \\
\hline 44 & 2003 & 6 & 10 & 8 & 40 & 32.05 & 23 & 30.22 & 121 & 41.95 & 32.31 & 6.48 & 169.2 & 172.3 & DOS & before \\
\hline 45 & 2003 & 8 & 11 & 16 & 30 & 13.81 & 24 & 35.55 & 121 & 33.57 & 58.49 & 5.38 & 47.4 & 75.3 & DOS & before \\
\hline 46 & 2003 & 12 & 10 & 4 & 38 & 13.52 & 23 & 4.00 & 121 & 23.89 & 17.73 & 6.42 & 217.3 & 218.1 & DOS & before \\
\hline 47 & 2004 & 10 & 15 & 4 & 8 & 50.18 & 24 & 27.74 & 122 & 51.10 & 91.03 & 7.10 & 147.0 & 172.9 & DOS & before \\
\hline 48 & 2004 & 10 & 23 & 14 & 4 & 27.51 & 25 & 0.80 & 121 & 33.83 & 9.49 & 3.73 & 3.4 & 10.1 & DOS & before \\
\hline 49 & 2004 & 11 & 8 & 15 & 54 & 55.86 & 23 & 47.69 & 122 & 45.62 & 10.00 & 6.58 & 184.4 & 184.7 & DOS & before \\
\hline 50 & 2004 & 11 & 11 & 2 & 16 & 44.50 & 24 & 18.70 & 122 & 9.48 & 27.26 & 6.09 & 100.9 & 104.5 & DOS & before \\
\hline 51 & 2005 & 3 & 5 & 19 & 6 & 51.73 & 24 & 39.28 & 121 & 50.45 & 6.39 & 5.90 & 51.1 & 51.5 & DOS & before \\
\hline 51 & 2005 & 3 & 5 & 19 & 8 & 0.09 & 24 & 39.19 & 121 & 47.86 & 6.95 & 5.96 & 48.7 & 49.2 & DOS & before \\
\hline 52 & 2005 & 4 & 30 & 14 & 48 & 17.23 & 24 & 2.11 & 121 & 37.47 & 8.45 & 5.62 & 109.6 & 110.0 & DOS & before \\
\hline 53 & 2005 & 6 & 1 & 16 & 20 & 5.66 & 24 & 38.20 & 122 & 3.98 & 64.78 & 6.00 & 68.7 & 94.4 & DOS & before \\
\hline 54 & 2005 & 9 & 6 & 1 & 16 & 0.41 & 23 & 57.49 & 122 & 17.01 & 16.76 & 6.00 & 140.3 & 141.3 & DOS & before \\
\hline 55 & 2005 & 10 & 5 & 16 & 16 & 35.14 & 24 & 50.62 & 121 & 38.16 & 73.35 & 4.84 & 22.1 & 76.6 & DOS & before \\
\hline 56 & 2005 & 10 & 15 & 15 & 51 & 4.36 & 25 & 5.98 & 123 & 48.45 & 190.85 & 7.02 & 229.6 & 298.5 & DOS & before \\
\hline 57 & 2005 & 11 & 29 & 22 & 41 & 49.84 & 24 & 45.18 & 122 & 2.02 & 68.04 & 5.51 & 58.7 & 89.9 & DOS & before \\
\hline 58 & 2005 & 12 & 5 & 10 & 15 & 29.98 & 25 & 0.20 & 121 & 34.54 & 10.68 & 3.68 & 4.8 & 11.7 & DOS & before \\
\hline 59 & 2006 & 4 & 1 & 10 & 2 & 19.54 & 22 & 53.01 & 121 & 4.84 & 7.20 & 6.23 & 241.6 & 241.8 & DOS & before \\
\hline 60 & 2006 & 4 & 15 & 22 & 40 & 55.37 & 22 & 51.33 & 121 & 18.21 & 17.90 & 6.04 & 241.5 & 242.2 & DOS & before \\
\hline
\end{tabular}




\begin{tabular}{|c|c|c|c|c|c|c|c|c|c|c|c|c|c|c|c|c|}
\hline \multicolumn{17}{|c|}{ CWB Earthquake Catalogue for Tai-Power building station (TAPBA4) } \\
\hline 編號 & 年 & 月 & 日 & 時 & 分 & 秒 & & 韋度 & & 陪度 & 深度 & 規模 & 震央距 & 震源距 & 主機 & 結構補強 \\
\hline \multirow{2}{*}{ No. } & year & month & day & hour & $\min$ & sec & & itude & long & situde & depth & \multirow{2}{*}{ ML } & $\mathbf{k m}$ & $\mathbf{k m}$ & \multirow{2}{*}{$\begin{array}{l}\text { logging } \\
\text { system }\end{array}$} & \multirow{2}{*}{$\begin{array}{c}\text { Structure } \\
\text { reinforcement }\end{array}$} \\
\hline & \multicolumn{6}{|c|}{ Event time(UTC) } & \multicolumn{5}{|c|}{ EQ location and depth } & & hypo-dist & epi-dist & & \\
\hline 61 & 2006 & 7 & 28 & 7 & 40 & 10.43 & 23 & 57.97 & 122 & 39.48 & 27.97 & 6.02 & 163.4 & 165.8 & DOS & before \\
\hline 62 & 2006 & 10 & 12 & 14 & 46 & 29.29 & 23 & 57.83 & 122 & 38.71 & 25.26 & 5.80 & 162.7 & 164.6 & DOS & before \\
\hline 63 & 2006 & 12 & 26 & 12 & 26 & 21.00 & 21 & 41.24 & 120 & 33.32 & 44.11 & 6.96 & 383.4 & 386.0 & DOS & before \\
\hline 64 & 2006 & 12 & 26 & 12 & 34 & 15.13 & 21 & 58.19 & 120 & 25.18 & 50.22 & 6.99 & 357.3 & 360.8 & DOS & before \\
\hline 65 & 2007 & 9 & 6 & 17 & 51 & 26.92 & 24 & 16.68 & 122 & 15.25 & 54.01 & 6.63 & 110.1 & 122.6 & DOS & before \\
\hline 66 & 2008 & 5 & 10 & 19 & 42 & 0.98 & 23 & 56.95 & 122 & 31.93 & 25.02 & 5.64 & 156.2 & 158.2 & DOS & before \\
\hline 67 & 2008 & 6 & 1 & 16 & 59 & 23.74 & 24 & 51.65 & 121 & 47.42 & 92.31 & 5.83 & 31.5 & 97.5 & DOS & before \\
\hline 68 & 2009 & 1 & 3 & 22 & 4 & 34.97 & 24 & 9.21 & 121 & 43.99 & 7.46 & 5.10 & 98.2 & 98.5 & WIN & working \\
\hline 69 & 2009 & 1 & 15 & 4 & 48 & 25.99 & 24 & 52.62 & 122 & 1.37 & 4.91 & 4.14 & 52.1 & 52.3 & WIN & working \\
\hline 70 & 2009 & 4 & 17 & 12 & 37 & 48.89 & 23 & 55.02 & 121 & 40.89 & 43.43 & 5.33 & 123.3 & 130.7 & WIN & working \\
\hline 71 & 2009 & 5 & 15 & 14 & 31 & 3.41 & 24 & 10.62 & 121 & 46.41 & 11.76 & 4.60 & 96.6 & 97.4 & WIN & working \\
\hline 72 & 2009 & 6 & 24 & 21 & 9 & 53.84 & 24 & 1.65 & 122 & 17.15 & 21.85 & 5.04 & 134.0 & 135.8 & WIN & working \\
\hline 73 & 2009 & 6 & 28 & 9 & 34 & 56.19 & 24 & 10.94 & 121 & 45.20 & 12.88 & 5.26 & 95.6 & 96.4 & WIN & working \\
\hline 74 & 2009 & 6 & 28 & 9 & 52 & 45.28 & 24 & 10.97 & 121 & 46.08 & 13.97 & 4.80 & 95.9 & 96.9 & WIN & working \\
\hline 75 & 2009 & 7 & 13 & 18 & 5 & 2.59 & 24 & 1.37 & 122 & 13.16 & 18.08 & 6.00 & 130.7 & 132.0 & WIN & working \\
\hline 76 & 2009 & 7 & 13 & 20 & 28 & 52.97 & 24 & 4.97 & 122 & 11.21 & 16.93 & 5.16 & 123.3 & 124.5 & WIN & working \\
\hline 77 & 2009 & 7 & 16 & 10 & 48 & 13.80 & 24 & 1.05 & 122 & 17.48 & 21.37 & 5.40 & 135.3 & 136.9 & WIN & working \\
\hline 78 & 2009 & 7 & 16 & 18 & 42 & 47.73 & 23 & 59.93 & 122 & 17.49 & 20.76 & 5.09 & 137.0 & 138.5 & WIN & working \\
\hline 79 & 2009 & 7 & 21 & 6 & 58 & 11.56 & 24 & 4.87 & 121 & 40.20 & 8.68 & 4.73 & 105.1 & 105.4 & WIN & working \\
\hline 80 & 2009 & 7 & 26 & 1 & 0 & 12.37 & 23 & 41.12 & 120 & 57.40 & 14.29 & 5.35 & 159.1 & 159.8 & WIN & working \\
\hline 81 & 2009 & 7 & 26 & 6 & 10 & 59.79 & 23 & 25.75 & 121 & 19.07 & 12.52 & 5.38 & 177.9 & 178.4 & WIN & working \\
\hline 82 & 2009 & 7 & 29 & 13 & 9 & 46.83 & 24 & 15.21 & 121 & 46.65 & 14.39 & 4.66 & 88.6 & 89.7 & WIN & working \\
\hline 83 & 2009 & 8 & 2 & 11 & 34 & 47.61 & 23 & 49.81 & 121 & 2.18 & 22.81 & 4.76 & 141.2 & 143.0 & WIN & working \\
\hline 84 & 2009 & 8 & 17 & 0 & 5 & 45.85 & 23 & 22.28 & 123 & 52.65 & 43.27 & 6.75 & 300.3 & 303.4 & WIN & working \\
\hline 85 & 2009 & 8 & 17 & 10 & 10 & 55.42 & 23 & 19.39 & 123 & 39.99 & 31.57 & 5.94 & 287.2 & 288.9 & WIN & working \\
\hline 86 & 2009 & 8 & 17 & 10 & 15 & 6.66 & 23 & 21.31 & 123 & 33.76 & 55.00 & 5.42 & 276.9 & 282.3 & WIN & working \\
\hline 87 & 2009 & 10 & 3 & 17 & 36 & 6.28 & 23 & 38.85 & 121 & 34.74 & 29.15 & 6.09 & 152.4 & 155.2 & WIN & working \\
\hline 88 & 2009 & 10 & 22 & 20 & 46 & 24.33 & 24 & 16.70 & 121 & 46.65 & 20.19 & 4.90 & 85.9 & 88.2 & WIN & working \\
\hline 89 & 2009 & 11 & 5 & 9 & 32 & 57.66 & 23 & 47.34 & 120 & 43.12 & 24.08 & 6.15 & 159.4 & 161.2 & WIN & working \\
\hline 90 & 2009 & 11 & 5 & 11 & 34 & 21.26 & 23 & 46.13 & 120 & 45.31 & 23.95 & 5.74 & 159.5 & 161.3 & WIN & working \\
\hline 91 & 2009 & 11 & 15 & 14 & 47 & 49.14 & 24 & 56.76 & 122 & 10.45 & 125.39 & 5.52 & 65.4 & 141.4 & WIN & working \\
\hline 92 & 2009 & 11 & 22 & 21 & 46 & 10.03 & 24 & 29.69 & 121 & 45.72 & 65.07 & 4.80 & 62.7 & 90.3 & WIN & working \\
\hline 93 & 2009 & 12 & 19 & 13 & 2 & 16.34 & 23 & 47.28 & 121 & 39.80 & 43.78 & 6.92 & 137.4 & 144.2 & WIN & working \\
\hline 94 & 2010 & 1 & 4 & 19 & 27 & 37.38 & 24 & 11.05 & 121 & 49.97 & 46.05 & 5.46 & 97.6 & 107.9 & WIN & working \\
\hline 95 & 2010 & 1 & 19 & 6 & 9 & 26.79 & 23 & 49.29 & 121 & 40.55 & 41.01 & 5.61 & 133.8 & 139.9 & WIN & working \\
\hline 96 & 2010 & 2 & 7 & 6 & 10 & 0.25 & 23 & 19.77 & 123 & 45.94 & 87.96 & 6.63 & 294.4 & 307.2 & WIN & working \\
\hline 97 & 2010 & 2 & 12 & 2 & 42 & 38.62 & 23 & 53.83 & 121 & 4.63 & 18.39 & 5.23 & 132.7 & 134.0 & WIN & working \\
\hline 98 & 2010 & 2 & 22 & 5 & 21 & 4.73 & 24 & 3.03 & 122 & 58.13 & 35.57 & 5.62 & 180.9 & 184.4 & WIN & working \\
\hline 99 & 2010 & 3 & 4 & 0 & 18 & 52.14 & 22 & 58.15 & 120 & 42.40 & 22.64 & 6.42 & 242.6 & 243.7 & WIN & working \\
\hline 100 & 2010 & 3 & 4 & 8 & 16 & 16.34 & 22 & 57.47 & 120 & 38.07 & 19.02 & 5.72 & 246.4 & 247.2 & WIN & working \\
\hline 101 & 2010 & 3 & 18 & 9 & 1 & 36.42 & 24 & 23.44 & 121 & 57.83 & 30.99 & 4.74 & 82.3 & 88.0 & WIN & working \\
\hline 102 & 2010 & 4 & 11 & 4 & 57 & 30.53 & 23 & 16.04 & 122 & 5.97 & 30.30 & 5.40 & 203.0 & 205.3 & WIN & working \\
\hline 103 & 2010 & 4 & 23 & 1 & 49 & 48.42 & 24 & 36.27 & 122 & 19.79 & 85.03 & 5.02 & 92.9 & 125.9 & WIN & working \\
\hline
\end{tabular}


CWB Earthquake Catalogue for Tai-Power building station (TAPBA4)

\begin{tabular}{|c|c|c|c|c|c|c|c|c|c|c|c|c|c|c|c|c|}
\hline \multirow{3}{*}{$\begin{array}{l}\text { 編號 } \\
\text { No. }\end{array}$} & \multirow{3}{*}{$\begin{array}{c}\text { 年 } \\
\text { year }\end{array}$} & \multirow{2}{*}{$\begin{array}{c}\text { 月 } \\
\text { month }\end{array}$} & \multirow{2}{*}{$\frac{\text { 日 }}{\text { day }}$} & \multirow{2}{*}{ 時 } & \multirow{2}{*}{ 分 } & \multirow{3}{*}{$\begin{array}{c}\text { 秒 } \\
\text { sec }\end{array}$} & \multicolumn{2}{|c|}{ 緯度 } & \multicolumn{2}{|c|}{ 經度 } & \multirow{2}{*}{$\begin{array}{c}\text { 深度 } \\
\text { depth }\end{array}$} & 規模 & \multirow{2}{*}{$\begin{array}{c}\text { 震央距 } \\
\mathbf{k m}\end{array}$} & \multirow{2}{*}{$\begin{array}{c}\text { 震源距 } \\
\mathbf{k m}\end{array}$} & \multirow{3}{*}{$\begin{array}{c}\text { 主機 } \\
\begin{array}{l}\text { logging } \\
\text { system }\end{array}\end{array}$} & \multirow{3}{*}{$\begin{array}{c}\text { 結構補強 } \\
\begin{array}{c}\text { Structure } \\
\text { reinforcement }\end{array}\end{array}$} \\
\hline & & & & & & & \multicolumn{2}{|c|}{ latitude } & \multicolumn{2}{|c|}{ longitude } & & \multirow{2}{*}{ ML } & & & & \\
\hline & & \multicolumn{4}{|c|}{ Event time(UTC) } & & & EQ loc & ation & ind dep & & & hypo-dist & epi-dist & & \\
\hline 104 & 2010 & 4 & 26 & 2 & 59 & 51.03 & 22 & 8.95 & 123 & 44.69 & 73.35 & 6.77 & 390.7 & 397.5 & WIN & working \\
\hline 105 & 2010 & 6 & 13 & 21 & 11 & 25.12 & 24 & 36.14 & 121 & 21.04 & 8.84 & 4.33 & 49.6 & 50.4 & WIN & working \\
\hline 106 & 2010 & 6 & 15 & 0 & 31 & 17.99 & 24 & 2.57 & 121 & 37.27 & 16.73 & 5.53 & 108.8 & 110.0 & WIN & working \\
\hline 107 & 2010 & 6 & 18 & 1 & 8 & 43.59 & 24 & 7.38 & 121 & 43.23 & 10.81 & 4.70 & 101.3 & 101.9 & WIN & working \\
\hline 108 & 2010 & 6 & 26 & 18 & 5 & 51.80 & 24 & 39.01 & 121 & 33.66 & 67.96 & 5.11 & 41.0 & 79.4 & WIN & working \\
\hline 109 & 2010 & 6 & 27 & 20 & 33 & 26.93 & 25 & 2.44 & 122 & 22.74 & 15.23 & 4.93 & 85.6 & 86.9 & WIN & working \\
\hline 110 & 2010 & 7 & 2 & 19 & 11 & 32.40 & 22 & 51.30 & 120 & 40.90 & 17.80 & 5.14 & 255.5 & 256.1 & WIN & working \\
\hline 111 & 2010 & 7 & 8 & 19 & 43 & 37.51 & 24 & 20.83 & 122 & 2.19 & 19.27 & 5.25 & 90.4 & 92.4 & WIN & working \\
\hline 112 & 2010 & 7 & 9 & 0 & 41 & 19.52 & 24 & 41.75 & 122 & 36.76 & 113.62 & 5.77 & 114.9 & 161.6 & WIN & working \\
\hline 113 & 2010 & 7 & 18 & 13 & 3 & 24.69 & 24 & 0.02 & 122 & 26.60 & 24.33 & 5.20 & 146.0 & 148.1 & WIN & working \\
\hline 114 & 2010 & 7 & 25 & 3 & 52 & 10.21 & 22 & 50.33 & 120 & 41.61 & 19.60 & 5.65 & 256.7 & 257.5 & WIN & working \\
\hline 115 & 2010 & 8 & 21 & 16 & 38 & 0.03 & 23 & 35.07 & 121 & 35.32 & 40.15 & 5.32 & 159.5 & 164.4 & WIN & working \\
\hline 116 & 2010 & 8 & 21 & 18 & 39 & 21.61 & 24 & 48.59 & 121 & 55.10 & 9.74 & 4.65 & 45.4 & 46.5 & WIN & working \\
\hline 117 & 2010 & 8 & 21 & 18 & 48 & 0.71 & 24 & 48.43 & 121 & 55.20 & 5.73 & 4.80 & 45.7 & 46.1 & WIN & working \\
\hline 118 & 2010 & 8 & 30 & 8 & 45 & 9.31 & 24 & 57.18 & 122 & 12.36 & 15.02 & 5.16 & 68.5 & 70.1 & WIN & working \\
\hline 119 & 2010 & 9 & 28 & 17 & 33 & 53.18 & 24 & 7.54 & 121 & 41.79 & 9.01 & 5.02 & 100.6 & 101.0 & WIN & working \\
\hline 120 & 2010 & 9 & 30 & 19 & 56 & 0.41 & 24 & 49.54 & 121 & 49.32 & 96.61 & 4.89 & 36.3 & 103.2 & WIN & working \\
\hline 121 & 2010 & 10 & 2 & 19 & 23 & 12.36 & 24 & 21.51 & 121 & 47.95 & 19.38 & 5.09 & 78.2 & 80.5 & WIN & working \\
\hline 122 & 2010 & 11 & 12 & 13 & 8 & 49.57 & 24 & 6.20 & 122 & 28.85 & 26.12 & 5.30 & 139.9 & 142.3 & WIN & working \\
\hline 123 & 2010 & 11 & 21 & 12 & 31 & 45.64 & 23 & 51.15 & 121 & 41.14 & 46.87 & 6.14 & 130.5 & 138.7 & WIN & working \\
\hline 124 & 2010 & 11 & 26 & 15 & 13 & 44.65 & 24 & 12.28 & 121 & 47.74 & 13.45 & 4.84 & 94.3 & 95.2 & WIN & working \\
\hline 125 & 2011 & 1 & 10 & 22 & 41 & 44.70 & 24 & 35.31 & 122 & 2.74 & 13.25 & 4.37 & 70.6 & 71.8 & WIN & working \\
\hline 126 & 2011 & 1 & 12 & 3 & 53 & 8.90 & 24 & 21.10 & 122 & 2.23 & 25.57 & 4.55 & 90.0 & 93.6 & WIN & working \\
\hline 127 & 2011 & 2 & 1 & 8 & 16 & 31.54 & 24 & 12.52 & 121 & 48.28 & 18.34 & 5.46 & 94.1 & 95.9 & WIN & working \\
\hline 128 & 2011 & 2 & 2 & 17 & 32 & 28.95 & 25 & 8.77 & 121 & 33.21 & 7.53 & 3.09 & 14.5 & 16.3 & WIN & working \\
\hline 129 & 2011 & 3 & 20 & 8 & 0 & 51.19 & 22 & 26.52 & 121 & 22.83 & 27.46 & 5.77 & 286.8 & 288.1 & WIN & after \\
\hline 130 & 2011 & 4 & 16 & 1 & 11 & 10.91 & 25 & 9.58 & 124 & 1.70 & 146.88 & 6.23 & 252.1 & 291.7 & WIN & after \\
\hline 131 & 2011 & 4 & 30 & 8 & 35 & 38.35 & 24 & 39.02 & 121 & 48.51 & 75.02 & 5.81 & 49.6 & 89.9 & WIN & after \\
\hline 132 & 2011 & 5 & 3 & 15 & 52 & 34.41 & 23 & 56.07 & 121 & 42.32 & 41.15 & 5.22 & 121.7 & 128.5 & WIN & after \\
\hline 133 & 2011 & 5 & 7 & 8 & 35 & 33.35 & 24 & 27.93 & 121 & 57.88 & 13.48 & 4.55 & 75.5 & 76.6 & WIN & after \\
\hline 134 & 2011 & 5 & 22 & 1 & 34 & 11.94 & 24 & 7.05 & 121 & 45.83 & 6.05 & 4.97 & 102.8 & 103.0 & WIN & after \\
\hline 135 & 2011 & 5 & 22 & 21 & 7 & 15.96 & 23 & 52.83 & 121 & 3.59 & 19.25 & 4.65 & 135.1 & 136.5 & WIN & after \\
\hline 136 & 2011 & 7 & 3 & 12 & 30 & 44.09 & 24 & 40.31 & 121 & 53.96 & 67.95 & 4.79 & 53.5 & 86.5 & WIN & after \\
\hline 137 & 2011 & 7 & 12 & 11 & 17 & 10.97 & 23 & 30.73 & 121 & 31.46 & 31.23 & 5.28 & 167.4 & 170.3 & WIN & after \\
\hline 138 & 2011 & 9 & 7 & 4 & 23 & 6.24 & 24 & 50.85 & 121 & 51.68 & 106.04 & 4.05 & 38.4 & 112.8 & WIN & after \\
\hline 139 & 2011 & 9 & 21 & 22 & 18 & 33.38 & 24 & 5.19 & 121 & 40.37 & 17.18 & 5.13 & 104.5 & 105.9 & WIN & after \\
\hline 140 & 2011 & 10 & 30 & 3 & 23 & 43.75 & 25 & 18.80 & 123 & 9.36 & 215.77 & 6.27 & 166.9 & 272.8 & WIN & after \\
\hline 141 & 2011 & 12 & 4 & 10 & 13 & 4.43 & 24 & 39.80 & 122 & 2.94 & 62.80 & 4.93 & 65.5 & 90.8 & WIN & after \\
\hline 142 & 2012 & 2 & 26 & 2 & 35 & 0.43 & 22 & 45.14 & 120 & 45.28 & 26.31 & 6.35 & 263.9 & 265.2 & WIN & after \\
\hline 143 & 2012 & 4 & 19 & 1 & 58 & 8.57 & 24 & 8.07 & 121 & 40.15 & 29.09 & 5.46 & 99.2 & 103.4 & WIN & after \\
\hline 144 & 2012 & 6 & 13 & 8 & 22 & 20.40 & 24 & 45.72 & 121 & 15.65 & 10.22 & 4.66 & 39.3 & 40.6 & WIN & after \\
\hline 145 & 2012 & 6 & 13 & 14 & 41 & 6.13 & 24 & 45.76 & 121 & 15.70 & 10.19 & 4.59 & 39.2 & 40.5 & WIN & after \\
\hline 146 & 2012 & 8 & 14 & 10 & 55 & 43.35 & 24 & 3.16 & 121 & 30.68 & 21.83 & 5.18 & 107.3 & 109.5 & WIN & after \\
\hline
\end{tabular}




\begin{tabular}{|c|c|c|c|c|c|c|c|c|c|c|c|c|c|c|c|c|}
\hline \multicolumn{17}{|c|}{ CWB Earthquake Catalogue for Tai-Power building station (TAPBA4) } \\
\hline 編號 & 年 & 月 & 日 & 時 & 分 & 秒 & & 路 & & 度 & 深度 & 規模 & 震央距 & 震源距 & 主機 & 結構補強 \\
\hline \multirow{2}{*}{ No. } & year & month & day & hour & $\min$ & sec & & itude & lon & itude & depth & \multirow{2}{*}{ ML } & km & km & \multirow{2}{*}{$\begin{array}{l}\text { logging } \\
\text { system }\end{array}$} & \multirow{2}{*}{$\begin{array}{c}\text { Structure } \\
\text { reinforcement }\end{array}$} \\
\hline & \multicolumn{6}{|c|}{ Event time(UTC) } & \multicolumn{5}{|c|}{ EQ location and depth } & & hypo-dist & epi-dist & & \\
\hline 147 & 2012 & 8 & 31 & 12 & 11 & 39.63 & 24 & 43.44 & 120 & 52.67 & 10.01 & 5.04 & 73.5 & 74.1 & WIN & after \\
\hline 148 & 2012 & 8 & 31 & 12 & 23 & 54.18 & 24 & 43.50 & 120 & 52.75 & 9.86 & 4.81 & 73.3 & 73.9 & WIN & after \\
\hline 149 & 2013 & 1 & 7 & 6 & 49 & 6.73 & 24 & 29.02 & 122 & 50.54 & 69.43 & 5.71 & 145.2 & 160.9 & WIN & after \\
\hline 150 & 2013 & 1 & 17 & 8 & 30 & 41.85 & 24 & 26.34 & 121 & 58.71 & 13.65 & 5.08 & 78.7 & 79.8 & WIN & after \\
\hline 151 & 2013 & 1 & 20 & 19 & 9 & 46.44 & 24 & 42.17 & 122 & 31.12 & 108.22 & 5.57 & 105.7 & 151.3 & WIN & after \\
\hline 152 & 2013 & 2 & 2 & 3 & 39 & 52.44 & 23 & 44.83 & 121 & 58.69 & 35.04 & 5.60 & 148.4 & 152.4 & WIN & after \\
\hline 153 & 2013 & 2 & 17 & 1 & 32 & 7.36 & 24 & 19.03 & 121 & 26.93 & 6.33 & 4.64 & 78.3 & 78.6 & WIN & after \\
\hline 154 & 2013 & 3 & 7 & 3 & 36 & 45.68 & 24 & 18.05 & 121 & 27.44 & 5.55 & 5.87 & 80.0 & 80.2 & WIN & after \\
\hline 155 & 2013 & 3 & 27 & 2 & 3 & 19.63 & 23 & 54.13 & 121 & 3.16 & 19.43 & 6.24 & 133.1 & 134.5 & WIN & after \\
\hline
\end{tabular}

